\title{
DIE ANFÄNGE DES ANTISEMITISMUS IM KÖNIGREICH POLEN IN DER ZWEITEN HÄLFTE DES NEUNZEHNTEN JAHRHUNDERTS
}

Seit der großen Wanderungsbewegung im späten Mittelalter konzentrierte sich die Masse der aschkenasischen Juden auf dem Gebiet der alten polnischen Republik. Mit den Teilungen gelangten sie unter die Herrschaft dreier verschiedener Mächte, die weitaus meisten unter die Rußlands, das 1815 gemäß den Beschlüssen des Wiener Kongresses aus Teilen der annektierten Gebiete ein autonomes Königreich Polen (fortan kurz: Königreich) schuf. Für das gesamte russische Reich wurde das Niederlassungsrecht der Juden auf den sog. Ansiedlungsrayon beschränkt, der im wesentlichen die ehemals polnischen Gebiete, einschließlich des Köningreichs, umfaßte. 1865 lebten im Königreich über 700000 Anhänger des judaischen Glaubens; bis 1885 war diese Zahl auf beinah 1,1 Millionen gestiegen, wobei nach den offiziellen Angaben das Tempo des Wachstums der jüdischen das des Wachstums der christlichen Bevölkerung übertraf. U.a. war das auf den Zustrom aus den östlichen Teilen des Ansiedlungsrayons ins Königreich, wo den Juden 1862 die formale Gleichberechtigung gewährt worden war, zurückzuführen. Seit den achziger Jahren nahm der Zustrom durch die neuerliche Einengung des Ansiedlungsrayons noch zu.

Die jüdische Gemeinschaft im Königreich war wenig homogen. $\mathrm{Zu}$ scharfen Klassengegensätzen kamen kulturelle Unterschiede. In kultureller Hinsicht zerfiel die jüdische Gemeinschaft in drei Gruppen: Mitnageddim, Chassidim und Assimilierte, die voll an dem allgemeinen kulturellen Leben teilnahmen. Ein zunehmendes politisches Engagement führte gegen Ende des Jahrhunderts noch zu einer weiteren Differenzierung.

Von außen wirkten auf die Juden im Königreich vor allem drei Kulturen ein: die polnische, die russische und die deutsche, wobei der Einfluß der zuerst genannten weitaus am stärksten war. Während sich die Konservativen gegen eine Liquidierung der überkommenen Standesgrenzen zur Wehr setzten, nahm eine Reihe progressiver Gruppen die Polonisierung der Juden ausdrücklich in ihr Programm auf. Die Frage wurde Jahrzehnte lang leidenschaftlich diskutiert; aber je mehr Fortschritte die Assimilationsbe- 
wegung machte, desto mehr ließ die Begeisterung auf polnischer Seite nach. Statt dessen griff, von den russischen Behörden gefördert, ein militanter Antisemitismus um sich. An überlieferte Vorurteile anknüpfend, entwickelte sich dieser Antisemitismus, dessen Ideologie zunächst aus Westeuropa importiert war, zu einer eigenen Kraft, die endlich zu einem festen Bestandteil des polnischen Nationalismus wurde, dessen Bedürfnis, sich gegen die Juden abzugrenzen, zunehmend die Züge einer Obsession annahm.*

\section{Das traditionelle Judenbild}

Ainsi, si l'on veut savoir ce qu'est le Juif contemporain, c'est la conscience chrétienne qu'il faut interroger: il faut lui demander non pas ,,qu'est-ce qu'un Juif?" mais , qu'as-tu fait des Juifs?"

Le Juif est un homme que les autres hommes tiennent pour Juif [ . . .].'

Diese Definition von Sartre scheint treffend sowohl in bezug auf die europäische Geschichte im allgemeinen als auch die polnische im besonderen. Die Haltung gegenüber den Juden war durch die kulturellen Traditionen der europäischen Gesellschaften bedingt, wobei deren Ethnozentrismus und das christliche Erbe - im weitesten Sinn - die wichtigsten Determinanten waren. Der Ethnozentrismus, ein Element des Bewußtseins von lokalen Gruppen, ließ fragen ,,Was sind wir nicht?", um so das Rätsel ,Wer sind wir?" zu lösen. Die dichotomische Teilung der Welt in eine ,,eigene" und eine ,,fremde" Sphäre war außerordentlich bedeutsam für die Selbstbestimmung der Gruppen und Individuen und die Erkenntnis ihres Platzes in der Welt. Die „Fremden” spielten dabei die Rolle eines Instruments zur Feststellung der eigenen Identität. ${ }^{2}$ Diese ethnozentrische Sicht der Welt wurde überlagert durch den Gegensatz von Judaismus und christlicher Religion. Dadurch, daß das Christentum den Juden in seinen Mythen einen zentralen Ort einräumte, trug es dazu bei, daß im Bewußtsein der Europäer die Juden eine ganz besondere Rolle spielten. Die Juden waren für die Europäer nicht nur eine unter vielen fremden Gruppen, sondern wurden geradezu zum Inbegriff der Fremdheit, zu einem wesentlichen Bestandteil zunächst ihres christlichen, später - so besonders in Polen - des nationalen Bewußtseins. Diese Tradition beeinflußte nicht nur die

* Bei den folgenden Ausführungen handelt es sich um eine Übersetzung zweier Kapitel aus A. Cała, , Kwestia asymilacji Żydów w Królestwie Polskim (1864-1897). Postawy konflikty - stereotypy", mschr. Ms., Diss. Warschau 1984.

1 J.-P. Sartre, Réflexions sur la question juive, Paris 1954, S. 83f.

2 Vgl. J. Obrebski, ,Problem grup etnicznych w etnologii i jego socjologiczne ujecie”, in: Przeglad Socjologiczny, Bd 4 (1936), Nr 1-2, S. 117-96; A. Cala, ,,Stosunek ,SwójObcy' w kulturze ludowej", in: Etnografia Polska, Bd 26 (1983), Nr 2, S. 204-14. 
Wahrnehmung der Juden, die, obwohl Jahrhunderte am gleichen Orte wohnend, durchaus nicht fremd zu sein aufhörten, sondern bestimmten auch ihren Platz in der gesellschaftlichen Ordnung. ${ }^{3}$

Für die Mehrzahl der polnischen Katholiken war der Jude vor allem der „,Mörder Christi”, der durch sein verstocktes Festhalten am Judaismus Christus stets von neuem kreuzigte. Derartige religiöse Vorurteile prägten das Verhältnis zu dieser , unreinen" Gruppe, erklärten die ihr zugewiesene Rolle. Die katholische Doktrin war aber in diesem Punkt ambivalent. Während sie einerseits die Juden für den Tod des Gottessohns verantwortlich machte, sah sie andererseits in ihnen Zeugen des Mysteriums seines Leidens. Sie handelten in Ausführung des Willens Gottes, realisierten seine unerforschlichen Gedanken. Dadurch gehörten sie - verdammt, aber zugleich mit heiligem Siegel bezeichnet - der Sphäre des Sakralen an. ${ }^{4}$ Ein lebendiger Beweis für die Wahrheit des Evangeliums, waren sie auf besondere Weise verflochten in den Zyklus des Bestehens dieser Welt, um schließlich noch eine bedeutsame Rolle in der Apokalypse zu spielen.

Bei einem großen Teil der polnischen Gesellschaft war das Verhältnis zu den Juden nicht nur durch die Lehre der katholischen Kirche, sondern auch durch einen überkommenen Volksglauben geprägt. Einerseits waren die Juden als Mörder Christi schuld am Unheil dieser Welt, gefährlich; andererseits konnte diese Welt aber nicht ohne sie bestehen, ja erfültten sie in ihr eine bestimmte symbolische Funktion. In den Augen der Bauern konnte ohne sie der normale Vegetationszyklus nicht funktionieren, weshalb in den rituellen Aufführungen in der Zeit der Winterpause, die ausreichende Erträge im nächsten Jahr garantieren sollten, die Gestalt des Juden unerläßlich war. Der betreffende Schauspieler, der eine Maske und ein haariges Gewand trug, wünschte dem bäuerlichen Hausherrn Glück, bat um eine Gabe und riß Zoten. Er symbolisierte die lebenspendende Kraft und den Erfolg; denn der bäuerliche Wohlstand hing ja primär von der Fruchtbarkeit der Erde, der Tiere und der Menschen ab. Übernatürlicher Segen kam durch die Vermittlung Fremder. Das bis heute tief eingewurzelte Vorurteil von dem enormen Reichtum der Juden dürfte wohl in diesem Glauben seinen Ursprung haben.

Wenn aber der normale Lauf der Welt durch Hungersnöte, Epidemien und Naturkatastrophen gestört wurde, dann wurden die Fremden, besonders die Juden, dafür verantwortlich gemacht. Sie waren es, die die Brunnen vergifteten, Krankheiten verursachten und durch ihre Gebete am

3 Vgl. L. Poliakov, Histoire de l'antisémitisme, 4 Bde, Paris 1955-77.

4 Vgl. M. Eliade, Traité d'histoire des réligions, Paris 1964; ferner die Artikel von L. Mróz, R. Tomicki, K. Kubiak, E. Regulska, Z. Benedyktowicz und I. Markowska in Etnografia Polska, Bd 23 (1979), Nr 2. 
Laubhüttenfest Überschwemmungen bzw. Dürre heraufbeschworen. Sie konnten Unglück und Tod herbeiführen (noch heute begegnet man in ländlichen Gebieten der Überzeugung, man könne sich, indem man bei einem Rabbiner ein Gebet bestellt, aus der Entfernung an einem Feinde rächen). Zur Wiederherstellung des natürlichen Weltlaufs war ein Opfer nötig, weshalb ökonomische Krisen, Kriege und Hungersnöte oft mit blutigen antijüdischen Pogromen einhergingen.

Der Übergang vom normalen Alltag zur besonderen Notsituation wurde durch weitere Vorurteile vermittelt, die die zweideutige Rolle des "Fremden" erklären sollten. Dazu gehörte etwa die Vorstellung vom Ritualmord, d.h. daß Christen getötet würden, um mit ihrem Blut die Matze zuzubereiten, sowie die weitverbreitete Legende von der Entweihung der Hostien. Die beiden Vorwürfe hatten eine ähnliche Bedeutung; denn sie liefen beide darauf hinaus, daß die Juden Menschenfresser seien (denn die Hostie war ja der Leib Christi), also das oberste Tabu verletzten. Diese Überzeugung tauchte übrigens nicht nur in den Ideen über diese eine Gruppe auf. Die Zigeuner z.B. entführten kleine Kinder; andere Gruppen sahen sich ähnlichen Verdächtigungen ausgesetzt. ${ }^{5}$

Das vorstehend skizzierte Bild der Juden spielte in den späteren ökonomischen und sozialen Konflikten eine nicht geringe Rolle. In Polen wurden die Juden als besonderer Stand betrachtet, der nach der Art seiner Betätigung dem Bürgertum ähnelte, aber sich in religiöser Hinsicht davon unterschied und in der sozialen Hierarchie einen anderen Platz einnahm. Die Mechanismen, die das Verhalten der Vertreter verschiedener Stände in ihrem Umgang miteinander regelten, beschrieb Aleksander Hertz folgendermaßen:

Genau bestimmte Kennzeichen der Zugehörigkeit zu einer Kaste (Kleidung, Sprache, Tätigkeiten u.dergl.) erlaubten eine schnelle Klassifizierung einer Person, der man begegnete [. . . ]. Es war dies eine sehr weite Definition; sie umfaßte die emotionale Einstellung zu der betreffenden Person, ordnete sie einer bestimmten Berufs-, Kulturgruppe zu, machte sie zum Element eines bestimmten Wertsystems, schrieb ihr bestimmte psychische Merkmale zu.

In der Regel war darin ein Moment der Wertung enthalten. [ . . .]

Die Definition des Juden umfaßte eine ganze Welt von Glaubenssätzen, Ansichten, moralischen, politischen, juridischen Prinzipien, umfaßte seine ökonomischen Aktivitäten, wies ihm bestimmte Funktionen und Aufgaben in dieser Welt zu. So entstand ein sehr vielseitiges-systematisiertes, emotional bedingtes, wertendes - Stereotyp. ${ }^{6}$

5 Vgl. J. S. Bystroń, ,Megalomania narodowa”, in Tematy, które mi odradzano, Warschau 1980.

6 A. Hertz, Żydzi w kulturze polskiej, Paris 1961, S. 445. 
Wie alles, was das Ergebnis jahrhundertelanger historischer Erfahrungen ist, basierte dieses Stereotyp nicht auf objektiver Beobachtung und rationaler Analyse. Wertungen dieser Art wurden von allen sozialen Gruppen vorgenommen. Der Bauer war ein cham (Grobian) für Juden und für Bürger ebenso wie für die szlachta, den polnischen Adel; desgleichen war der Bürger ein $t y k$ (nach einem billigen Hanfkittel) und der Jude ein parch (Krätze) für alle anderen Stände. Diese Bezeichnungen waren trotz ihres pejorativen Klangs nicht notwendig ein Ausdruck scharfer sozialer Gegensätze. Geringschätzung und Verachtung für eine andere Gruppe schlossen friedliche Beziehungen nicht aus.

$\mathrm{Da}$ für den Bauern der Jude ein parch war, mußte noch kein Anzeichen von Antisemitismus sein, wenn wir unter Antisemitismus eine sich deutlich manifestierende feindliche Haltung gegenüber Juden verstehen. Der Bauer bestimmte, indem er den Juden parch nannte, den Platz der Kaste, die die Juden darstellten, beurteilte dieselbe, stellte ihre Position innerhalb der Gesamtstruktur des kollektiven Lebens fest. Die Bezeichung konnte abfällig sein, aber das bedeutete noch nicht Feindschaft. ${ }^{?}$

Die Juden nahmen in der gesellschaftlichen Rangordnung der alten Republik keineswegs den niedrigsten Platz ein. Jedenfalls lokalisierten sie sich selbst ziemlich weit oben, ja verglichen sich oft mit der szlachta. ${ }^{8}$ Ohne Zweifel hatten sie eine höhere Position als die leibeigenen Bauern. Stanistaw Schnür-Peplowski zitierte Berichte von Ausländern, laut denen der Jude in der bäuerlichen Dorfgemeinde eine Autorität war: er war eine Quelle von Informationen über die Welt, gab Rat, war Mittler zwischen dem Dorf und Gut und der Stadt. ${ }^{9}$ Er lieferte handwerkliche Erzeugnisse und ging mit Geld um, weshalb er mit ,,Wohlergehen" assoziiert wurde. In der Praxis war die Beziehung zu dieser Gruppe ambivalent. Die Urteile änderten sich je nach Situation und Art des Kontakts. Derselbe Mensch, der in vielen Fragen eine Autorität war, wurde als Händler verachtet. Diese Tätigkeit galt nicht als Arbeit. Aber obwohl Bauer wie Adliger den Händler einen ,,Schwindler" nannten, hörten sie nicht auf, seinen Rat und seine Dienste in Anspruch zu nehmen. Mehr noch - die negative Meinung von der Gruppe im ganzen stand freundschaftlichen Kontakten nicht im Wege. Ein altes Sprichwort lautete, daß jeder Adlige ,,seinen" Juden habe. Am wenigsten Kontakte mit den Juden hatte der Bürger; angesichts der kollidierenden Interessen waren die Kontakte eher antagonistischer

7 Ebd.

8 Vgl. B. D. Weinryb, The Jews of Poland, Philadelphia 1973, S. 160-75.

9 S. Schnür-Peplowski, Cudzoziemcy w Galicji (1787-1841), Krakau 1902. 
Natur. Aber auch viele Bürger sonderten eine Gruppe , angepaßter Juden" aus, mit denen sie engere Beziehungen unterhielten.

Es ist schwer feststellbar, bis wie weit ins neunzehnte Jahrhundert hinein jenes traditionelle Bild der Juden das Denken der Gebildeten bestimmte. Viele der fraglichen Urteile bzw. Vorurteile waren indessen den verschiedenen Teilen der polnischen Gesellschaft durchaus gemeinsam. Schockiert von dem Warschauer Pogrom von 1881, schrieb Eliza Orzeszkowa:

Unsere Ideen über Geschichte, Religion und Sitten der Juden sind einfach kindisch. Ewig steht - der lächerlichste Gegensatz unter der Sonne - neben Szymszelek und Abrahamek, die alle Merkmale des extremsten Naturalismus aufweisen, in unserer Phantasie der Jude, wie ihn das Mittelalter ausgemalt hat: ein beinah übernatürliches, geheimnisvolles Wesen, umweht von dem Grauen der begangenen Verbrechen und dem durch die lateinischen Exorzismen aus seinem teuflischen Rachen herausgetriebenen Schwefeldampf. Auf dem Grunde unserer Seele lauert noch, sich schamhaft vor dem Antlitz der modernen Wissenschaft verbergend, eine starke Neigung, zu glauben, daß die jüdische Religion gebiete, die Passah-Matze mit Christenblut zu bereiten. In unserem Gedächtnis steigen von Zeit zu Zeit dunkle Erinnerungen an irgendwelche Hostien auf, die irgendwann einmal gestohlen und an Türen genagelt wurden, an irgendwelche vergifteten Brunnen, an irgendeinen Schwarzen Tod, der auf dem Rücken der Juden in die christlichen Länder einfiel. Nimmer glauben wir noch wirklich an das alles. Aber - in unserer Einbildung glimmt noch ein Fünkchen von dem Schrecken, den unsere Kinderfrauen dort entfacht haben; es gibt noch durchaus aufgeklärte Häuser, die sich die halbwüchsigen Kinder an den Tagen vor dem jüdischen Passahfest zu verlassen fürchten, weil sie von Juden entführt werden könnten; diese Relikte aus vergangenen Zeiten, die in den gebildeten Klassen noch fortexistieren, bewahren in den ungebildeten Klassen noch ihr volles Dasein. ${ }^{10}$

Beschreibungen der im Volk verbreiteten Vorurteile gelangten kaum je in die Presse; aber einige lassen sich doch finden. 1885 zitierte Peltyn aus der Gazeta Kielecka einen Leserbrief aus Wloszczowa über die Schändung jüdischer Gräber durch Schäfer:

die durchgeführte Exhumierung ergab, daß dem einen der zwei Leichname beide und dem anderen ein Bein abgeschnitten war. Die dieser Untat Verdächtigten sollen Schäfer sein. ${ }^{11}$

${ }^{10}$ E. Orzeszkowa, O Żydach i kwestii żydowskiej, Wilna 1882, S. $66 f$.

11 S. C. Peltyn, ,Światla i cienie”, in: Izraelita, 1885, Nr 41, S. 331 . Samuel Cwi (Hirsch) Peltyn redigierte bis zu seinem Tod im Jahre 1896 das von ihm 1866 gegründete Wochenblatt Izraelita, das die Assimilierung der polnischen Juden zu Polen mosaischen Bekenntnisses befürwortete. 
Der verhaftete Schäfer hat sich schuldig bekannt, wobei er zu seiner Verteidigung anführte, daß schließlich jeder Schäfer für Zauberei einen ,,Juden” bzw. einen ,Gehenkten” habe, da darin der ,,Teufel" sitze. ${ }^{12}$

Als 1892 eine Cholera-Epidemie ausbrach, publizierte der Izraelita einen Aufruf des Warschauer Rabbinats, der zur Einstellung der rituellen Veranstaltungen aufforderte, die die Seuche bannen sollten.

Unsere Glaubensgenossen versammelten sich massenhaft auf den Friedhöfen zur Abhaltung von Hochzeitsfeiern für verkrüppelte Waisen, veranstalteten Umzüge durch die Stadt und führten noch andere Praktiken zur Abwehr der Gefahr aus. Diese auf alten Gebräuchen basierenden Praktiken sind an sich nichts Frevelhaftes; die Hochzeitsfeiern dienen philanthropischen Zwecken, die sehr löblichen, mit Gebet verbundenen Umzüge aber sollen den Geist erquicken und den Himmel gnädig stimmen. Da das alles aber in der Öffentlichkeit geschieht und Leute, die die eigentliche Bedeutung der erwähnten Praktiken nicht kennen, diese verkehrt deuten, verbreiten sich aus ihrem Anlaß durch Vermittlung der Zeitungen verschiedene Gerüchte und werden den Veranstaltungen verfehlte und schädliche Tendenzen zugeschrieben [. . .]. Das hat bereits zu diversen Konflikten und Mißverständnissen geführt, und die Fortsetzung könnte gefährliche Folgen haben. ${ }^{13}$

D.h. Gerüchte, insbesondere im russischsprachigen Varšavskij Dnevnik publizierte Andeutungen, nach denen die Juden die Seuche verbreiteten, konnten zu Pogromen führen. Wohl aus Furcht vor derartigen Unruhen wiederrief der Varšavskij Dnevnik schon bald jene Vorwürfe; nach dem

12 Ebd., Nr 43, S. 346. In der Volkskultur spielten die Schäfer häufig die Rolle von Heilkundigen, wobei sie verschiedene Akzessorien der schwarzen Kunst benutzten, u.a. Körperteile von ,Verdammten”, d.h. von Hingerichteten sowie verstorbenen Juden, Zigeunern usw. Schon in mittelalterlichen Quellen sind derartige Fälle vermerkt. Vgl. auch O. Kolberg, Dziela wszystkie, Bd 48, Wroclaw 1967, S. 303. Kolberg zitiert dort eine Notiz von K. Lange (Zapiski Statystyczne Kalendarza Naukowego, Przemyśl 1865, S. 89): ,Als infolge der schrecklichen Überschwemmung im Jahre 1845 im galizischen Weichselgebiet der Typhus ausbrach und die ausgehungerte Bevölkerung dezimierte, redete ein dubioser Urlauber aus der Gegend von Bojanów bei Rzeszów, der sich einige Bauern zu Hilfe genommen hatte, den Unglücklichen ein, daß das wirksamste Heilmittel gegen die Krankheit eine Brühe aus den Körpern toter Juden sei, und karrte einige Wochen lang für gute Bezahlung verschiedene Teile von Judenleichen an, die er auf dem Friedhof des Städtchens Rozwadów ausgegraben hatte. Die dummen Weiber brauten daraus einen ekelhaften Trank, mit dem sie natürlich die Kranken umbrachten, bis die Behörden und die alarmierten Juden endlich die Leichenschänder festnehmen konnten." Über einen ähnlichen Vorfall wurde im Kurier Warszawski, 1876, Nr 117, berichtet. Während ethnographischer Forschungen bin ich selbst noch 1976 entsprechenden Vorstellungen begegnet. Eine sechzigjährige Einwohnerin von Sieniawa (Wojewodschaft Rzeszów) behauptete im Brustton der Überzeugung: ,Wenn es dem Schäfer gutgehen soll, muß man im Schafstall einen Juden einmauern."

13 ,,Odezwa Warszawskiego Rabinatu”, in: Izraelita, 1892, Nr 42, S. 359. 
Izraelita, der den Text nachdruckte, wurde ausdrücklich konstatiert:

Bemühungen seitens der Juden zur Verbreitung der Krankheit unter den Christen auf die in der Korrespondenz dargelegte Weise wurden nicht bemerkt. Ebensowenig wurden Fälle festgestellt, daß Juden zur Verbreitung der Seuche unter den Christen Brunnen verunreinigt hätten. Ersonnen wurde von dem Korrespondenten auch die Nachricht von dem Fackelzug der Juden in der Nacht vom 25. auf den 26. September mit Musik, Tanz und Beschimpfung der unterwegs angetroffenen Christen. ${ }^{14}$

Die Beschuldigung, daß die Juden - infolge ihrer rituellen Unreinheit Seuchen erregten und Brunnen vergifteten, war ein altes, in ganz Europa verbreitetes Vorurteil, das bereits im elften Jahrhundert nachweisbar ist.

Ein anderer fest eingewurzelter Aberglaube war die Annahme, daß die Juden in ihren geheimnisvollen Riten Christenblut benutzten. Vom Mittelalter bis ins neunzehnte Jahrhundert wurden bei den Gerichten Fälle von ,,Ritualmord” anhängig gemacht; im letzten Viertel des neunzehnten Jahrhunderts erlebten Prozesse dieser Art eine eigentümliche Renaissance. Besonderes Aufsehen erregte 1883 eine langwierige Verhandlung in TiszaEszlar in Ungarn sowie 1903 der von den russischen Antisemiten initiierte Bejlis-Prozeß. Im Izraelita finden sich Berichte über ähnliche, wenngleich weniger sensationelle, Prozesse in Polen, z.B. in Uniejów bei Kalisz. ${ }^{15}$ Das Urteil lautete auf zwölf Jahre Verbannung; aber im Berufungsverfahren wurden die Angeklagten freigesprochen. In einer kurzen Notiz unterstrich Peltyn, daß die Richter der ersten Instanz Russen gewesen seien.

1885 berichtete der Izraelita über einen ähnlichen Prozeß in Danzig, dessen Szenario dem in Tisza-Eszlar glich. Ebenso wie dort begleitete ihn eine Hetzkampagne der antisemitischen Presse und wurde massiver Druck ausgeübt: Zeugen wurden eingeschüchtert, Aussagen erpreßt. Aber auch dieser Prozeß endete mit einem Freispruch.$^{16} \mathrm{Im}$ gleichen Jahr brachte der Izraelita eine Korrespondenz über einen Prozeß dieser Art in Luczyna im Gouvernement Witebsk, wo ein Ehepaar des Mords an einem Dienstmädchen beschuldigt wurde. Diesmal kam es zur Verurteilung - die antijüdische Kampagne in Rußland war bereits in vollem Gange. ${ }^{17}$ Ebenfalls 1885 fand in Krakau der Prozeß gegen die Familie Ritter statt, die der ,Ermordung eines christlichen Mädchens zu religiösen Zwecken" angeklagt war. Er rief Proteste des gesamten fortschrittlichen Teils der polnischen Gesellschaft hervor, in dessen Augen die Bestätigung des Urteils, das auf Tod

${ }^{14}$,Odwotanie nieprawdziwej wieści”, ebd.

15 S. C. Peltyn, ,Pogadanki", ebd., 1879, Nr 12.

16 , ,Z zagranicy”, ebd., 1885, Nr 16.

17 ,'Kronika z Cesarstwa", ebd., Nr 18. 
durch den Strang lautete, durch drei Instanzen der polnischen Gerichte in Galizien ein Skandal war. Erst im Berufungsverfahren in Wien wurden die Angeklagten freigesprochen. ${ }^{18}$

Ritualmord-Anklagen waren der unmittelbare Anlaß vieler - spontaner und organisierter - Pogrome. Die Verknüpfung dieses Vorurteils mit dem Passahfest war der Grund dafür, daß sie sich vorzugsweise in den Monaten März-April ereigneten. Über solch einen Pogrom bei Jarostaw berichtete der Izraelita im April 1869. ${ }^{19}$ Zwei Jahre später kamen Nachrichten über Unruhen in Odessa sowie in einigen Orten Rumäniens und Galiziens. ${ }^{20}$ 1875 schrieb Peltyn über einen Tumult in Warschau, 1878 über Unruhen in Kalisz und Umgebung. ${ }^{21}$ Die Gefahr von Pogromen verfolgte die Juden in Europa durch ihre ganze Geschichte. Besonders akut war sie um die christlichen Feiertage, für die den Juden ein bestimmtes Verhalten vorgeschrieben wurde. In vielen kleineren polischen Städten wurden sie gezwungen, am Fronleichnamsfest ihre Fenster zu schmücken, dem Bischof ihre Ehrerbietung zu bezeigen u.ä. Diese Sitte erhielt sich in vielen Orten bis in die dreißiger Jahre des zwanzigsten Jahrhunderts. Auch Peltyn meinte, daß sich ein Jude besser nicht in der Nähe einer Prozession zeigen, und wenn schon, dann sein Haupt entblößen sollte. ${ }^{22}$

Aberglauben und tiefsitzende Vorurteile wurden durch den Ende des neunzehnten Jahrhunderts aufkommenden Antisemitismus ausgenutzt und verstärkt, und auf sein intensives Wirken dürfte es zurückzuführen sein, daß sie bis heute lebenskräftig sind. Sie waren auch die Ursache für die vom Izraelita gewissenhaft registrierten mannigfaltigen Formen einer unscheinbaren Diskriminierung im tagtäglichen Verkehr. So klagte etwa der Kurier Lubelski, daß die Juden, die samstags im Sächsischen Garten spazieren gingen, die Hauptalleen okkupierten, während die Christen in den Seitenwegen ihre Zuflucht suchen mußten. ${ }^{23}$ Die Behörden von Sochaczew verboten den Juden, mit Christen zusammen im Fluß zu baden. ${ }^{24}$ Ferner berichtete Peltyn über die Diskriminierung jüdischer Patienten in einer Augenklinik. ${ }^{25} \mathrm{Zu}$ den alltäglichen Schikanen gehörte auch die Stö-

18 , ZZ zagranicy", ebd., Nr 36, 39.

19 L.J., ,,Korespondencja, Lwów, kwiecień”, ebd., 1869, Nr 17.

${ }^{20}$ S. C. Peltyn, , ,Bogactwo jako powód do excesów przeciwko Żydom”, ebd., 1871, Nr 18-19.

${ }_{21}$ Ders., ,,Pogadanki”, ebd., 1875, Nr 17; ,,Wytrwatości-do postepowych braci izraelitów", ebd., 1878, Nr 28.

22 Ders., ,,Pogadanki”, ebd., 1875, Nr 22; , Z tygodnia”, ebd., 1880, Nr 22; ,Z tygodnia", ebd., 1881, Nr 21 .

23 Ders., ,Pogadanki”, ebd., 1875, Nr 21.

24 X, ,Pogadanki”, ebd., 1875, Nr 28.

25 S. C. Peltyn, ,Pogadanki”, ebd., 1877, Nr 1 
rung jüdischer Leichenzüge, aus der sich der Warschauer Pöbel ein Gaudi zu machen pflegte. ${ }^{26}$

Die angeführten Beispiele vermitteln nur andeutungsweise eine Idee von der gesellschaftlichen Atmosphäre um die Juden. Sie war nicht besonders wohlwollend, hielt sich aber in den Grenzen der ,,normalen" Beziehungen zwischen den verschiedenen Ständen, wie sie Hertz in der zitierten Passage beschrieben hat. Sie unterschied sich nicht viel von der, die, was das Verhältnis von Stadt und Gut zu ihnen anging, die Bauern umgab. Ein klarer Unterschied bestand indessen darin, da $B$ niemand Pogrome gegen Bauern inszenierte.

Die Atmosphäre änderte sich nach dem Aufstand von 1863, wenn auch, wie sich später herausstellte, nicht total und nicht definitiv. Ende der fünfziger Jahre betrat die Gruppe der assimilierten Juden die politische Arena, was während des Konflikts zwischen dem Herausgeber des Kurier Warszawski Lesznowski und jungen Juden aus wohlhabenden und gebildeten Familien sichtbar wurde. ${ }^{27}$ Die Jahre 1861 und 1862 standen im Zeichen der Demonstrationen brüderlichen Einvernehmens zwischen Polen und Juden. Nach dem Zusammenbruch des Aufstands galt in der Publizistik die Konvention, über die Juden positiv zu schreiben - oder gar nicht. Danach aber kamen die zornigen jungen Positivisten ${ }^{28}$ deren entschiedenes soziales Programm auch die Polonisierung der Juden einschloß. Das alles spielte sich jedoch nur innerhalb der gebildeten Schichten ab, die die öffentliche Meinung bildeten, während sich im alltäglichen Leben, wie die angeführten Fälle zeigen, wenig änderte, vielmehr archaische Auffassungen ihre ungebrochene Kraft bewahrten.

Allerdings wurde durch die Assimilationsbewegung das traditionelle Bild der Beziehungen zwischen Polen und Juden in Frage gestellt. Die Assimilierten paßten nicht in dieses (es war schließlich schwierig, etwa in einem weltberühmten Gelehrten einen parch zu sehen); zugleich beunruhigten sie durch ihr Dasein. Die Reaktion war unterschiedlich: die einen

${ }^{26}$ Ders., ,ZZ tygodnia", ebd., 1880, Nr 38.

${ }^{27}$ Zum sog. ,,jüdischen Krieg" gibt es eine ausgedehnte Literatur. Vgl. u.a. K. Bartoszewicz, Wojna żydowska w roku 1859 . Poczatki asymilacji i antysemityzmu, Warschau 1913; S. Hirszhorn, Historia Żydów w Polsce od Sejmu Czteroletniego do wojny europejskiej, Warschau 1921; W. Ciełżyński, Prasa warszawska, Warschau 1962; A. Eisenbach, Kwestia równouprawienia Zydów w Królestwie Polskim, Warschau 1972.

${ }_{28}$ Anmerkung des Übersetzers: Gemeint sind die Vertreter des sog. Warschauer Positivismus, einer Strömung, die sich im Königreich nach dem Scheitern des Aufstands von 1863-64 entwickelte; ihr führender Ideologe war Aleksander Świętochowski, ihr führendes Organ der Przegla d Tygodniowy. Ihrer Weltanschaung nach Positivisten, propagierten sie auf dem Gebiet der nationalen Politik die Preisgabe der ,,romantischen" Aufstandsidee zugunsten einer Stärkung der Nation durch ,, organische Arbeit" im Rahmen der bestehenden politischen Verhältnisse. 
bejahten die neue Strömung (bei ambivalenter, oft feindlicher Einstellung zu den orthodoxen Juden); die anderen kultivierten eine antijüdische - und später antisemitische - Haltung; manchmal koexistierten beide Haltungen in derselben Person. Ich möchte hier Jerzy Jedlicki zitieren.

Dieser spezifische Widerstand, dieser Widerwille gegen die Anname des jüdischen Elements, gegen seine Assimilierung und die eigene Verschmelzung mit ihm erforderte nicht nur eine besondere Begründung, sondern auch [. . . ] ein entsprechendes Unterscheidungsmerkmal. Das einzige, das dafür in Frage kam, war das genealogische Kriterium. Das soll nicht heißen, da $\beta$ erst die Assimilierung den Rassismus hervorgebracht hätte [...]. Worum es geht, ist vielmehr, daß, solange sich fast die gesamte jüdische Gemeinschaft von der übrigen Bevölkerung so deutlich und in so vielen leicht angebbaren Hinsichten unterschied, der genetische Mystizismus [. . . ] durchaus kein notwendiger Bestandteil einer antijüdischen Einstellung war. Erst in dem Moment, als die Polonisierung nicht mehr nur ein sporadisches Phänomen war, sondern zu einer sozialen Strömung wurde [ . . .], geriet die antijüdische Obsession methodologisch in eine schwierige Lage [. . . ]. Aus dieser Lage gab es zwei Auswege. Der eine bestand darin, die polonisierten Individuen oder Gruppen als zur eigenen Gemeinschaft gehörig anzuerkennen und zugleich weiterhin eine feindliche Einstellung zu dem Reservat der echten Juden als Angehörigen einer anderen, ,,fremden" Gemeinschaft zu hegen [ . . . ]. Der andere Ausweg bestand in dem Rückgriff auf den Rassismus, der so aus einer zusätzlichen Begründung von sekundärer Bedeutung, die er früher war, zur einzigen verbleibenden Linie der ,,Verteidigung gegen das Judentum" wurde. ${ }^{29}$

Die zitierte Passage läßt sich auf die Entwicklung des Bewußtseins der polnischen Gesellschaft in der behandelten Epoche beziehen. Der Weg führte von dem traditionellen Bild des Juden über die ambivalente Einstellung zur Assimilationsbewegung bis zum modernen Antisemitismus, der gegen Ende des neunzehnten Jahrhunderts immer weitere Kreise der polnischen Gesellschaft zu erfassen begann.

\section{Der Antisemitismus}

Jan Jeleński (1848-1909) hatte viele Jahre hindurch als Telegraphist der Terespoler Eisenbahn gearbeitet. Er war Autodidakt. Seine journalistische Karriere begann er am Przeglad Tygodniowy, dem Organ der Positivisten. 1873 veröffentlichte er eine kürzere Abhandlung , Über die Dirigierung der Juden zur Arbeit in der Landwirtschaft". ${ }^{30}$ Seitdem wurden jüdische Probleme bei ihm zu einer Art Obsession. Die erste Broschüre

${ }^{29}$ J. Jedlicki, ,Co to znaczy Żyd - czyli meandry asymilacji”, unveröffentlichtes Manuskript.

30 J. Jeleński, O skierowaniu Żydów ku pracy w rolnictwie, Warschau 1873. 


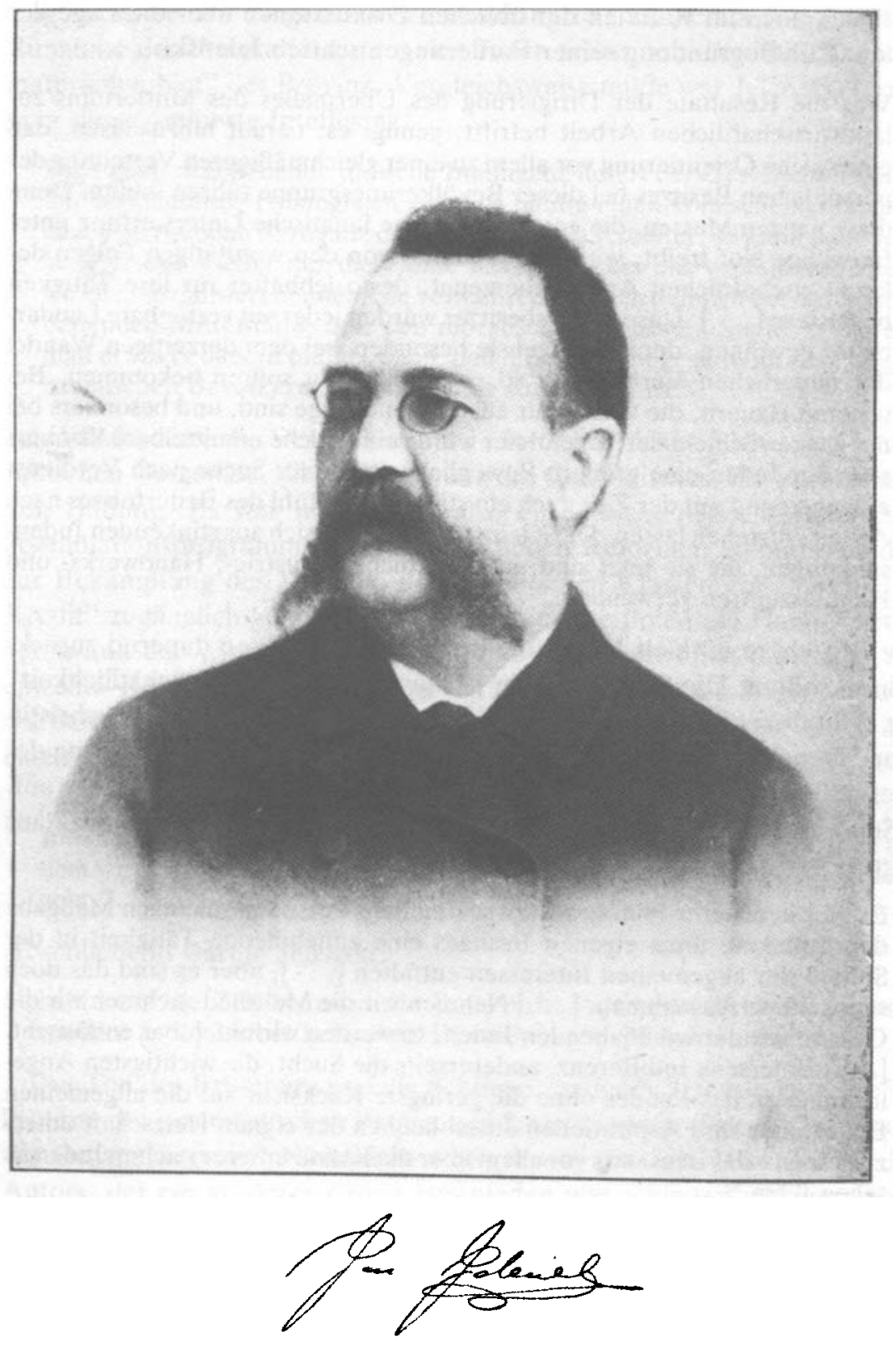

Jan Jeleński (1848-1909), Universitätsbibliothek Warschau 
hielt sich noch im Rahmen der üblichen Diskussionen über die Lage der Juden. Zur Begründung seiner Forderungen schrieb Jeleński:

Was die Resultate der Dirigierung des Übermaßes des Mittlertums zur landwirtschaftlichen Arbeit betrifft, genügt es, darauf hinzuweisen, daß eine solche Orientierung vor allem zu einer gleichmäßigeren Verteilung des persönlichen Besitzes bei dieser Bevölkerungsgruppe führen müßte. Denn diese ganzen Massen, die gegenwärtig eine fanatische Unterwerfung unter freiwillige Not treibt, würden sich dann, von den wohltätigen Folgen der landwirtschaftlichen Arbeit überzeugt, desto lebhafter für ihre Tätigkeit begeistern [. . . ]. Unsere Gutsbesitzer würden jederzeit verfügbare Landarbeiter gewinnen, deren Mangel sie besonders bei dem derzeitigen Wandel der bäuerlichen Verhältnisse so empfindlich zu spüren bekommen. Bei unseren Bauern, die von Natur aus faul und träge sind, und besonders bei der ganzen Schicht der Tagelöhner würde eine solche unmittelbare Konkurrenz der Juden eine größere Beweglichkeit bei der Suche nach Verdienst erzeugen und mit der Zeit auch ein stärkeres Gefühl des Bedürfnisses nach Arbeit entstehen lassen. Die Kleinstädte würden sich aus stinkenden Judensiedlungen, die sie jetzt sind, in ordentliche Industrie-, Handwerks- und Handelszentren verwandeln. ${ }^{31}$

Die Broschüre enthielt Ideen, die in Jeleńskis Arbeiten dauernd zurückkehren sollten. Die Schuld für die ,Unaufgeklärtheit und Schädlichkeit” der orthodoxen Massen gab er dem Talmud. Er rief zur Bildung ,,christlicher" Genossenschaften und Handelsgesellschaften zur ,,Beseitigung des übermäßigen maklerischen und händlerischen Mittlertums" der Juden auf.

Seine zweite Abhandlung, die 1877 erschien, war im Ton schon weitaus aggressiver. Scharf kritisierte Jeleński die assimilierte Plutokratie.

Es gibt in unserer Plutokratie zwar durchaus Personen, die nach Maßgabe der Zunahme ihres eigenen Besitzes eine zunehmende Tätigkeit in der Sphäre der allgemeinen Interessen entfalten [. . . ], aber es sind das doch sehr seltene Ausnahmen. [. . .] Nehmen wir die Mehrheit, nehmen wir die Gesamtheit der wohlhabenden Juden, so werden wir unfehlbar enttäuscht. [. . . ] Einerseits Indifferenz, andererseits die Sucht, die wichtigsten Angelegenheiten des Landes ohne die geringste Rücksicht auf die allgemeinen Bedürfnisse und Aspirationen ausschließlich der eignen Herrschaft unterzuordnen - das ist es, was vor allem über die Klasse unserer reichen Juden zu sagen wäre. ${ }^{32}$

Eine ebenso schlechte Meinung hatte Jeleński von der , ungebildeten Masse der israelischen Bevölkerung". Ihre ökonomische Aktivität, die er als ,,verstohlenen Kramhandel" charakterisierte, war für ihn nicht nur unsolide, sondern schädlich; gerichtet auf die Übervorteilung der Kunden,

31 Ebd., S. 24f.

32 Ders., Żydzi, Niemcy i my, Warschau 1877, S. $16 \mathrm{f}$. 
trug sie in seinen Augen zur Verelendung der kleinen Städte bei, zur Zunahme des Proletariats unter den Juden selbst, zur ,,moralischen und materiellen Not" der Provinz. Vergleichsweise milde war Jeleńskis Urteil über die assimilierte Intelligenz.

Die mäßig wohlhabende jüdische Intelligenz liefert der Gesellschaft fähige und ausdauernde (wenngleich ziemlich häufig einen komischen Hochmut, eine übertriebene Arroganz demonstrierende) Arbeiter; so kann man denn andererseits wieder nur diese eine Klasse der bei uns wohnhaften Juden wirklich sozialisiert nennen. Sie vermehrt eigentlich den sich bei uns herausbildenden Mittelstand, d.h. den moralisch gesündesten Stand, und wenn man etwas bedauern müßte, dann, daß diese Schicht gegenüber der übrigen israelischen Bevölkerung zahlenmäßig so schwach ist. ${ }^{33}$

Jeleński forderte die Verstärkung des ,,fortschrittlichen Elements" in der jüdischen Gemeinde, die Eindämmung des Chassidismus, die Verbreitung von Bildung. Es war im Grunde also ein - nicht näher definiertes Assimilationsprogramm. An wirtschaftlichen Reformen empfahl er, daß zur Bekämpfung des Wuchers den arbeitenden Klassen ein ,,rationeller Kredit" zugänglich gemacht würde, daß sich die Polen am Handel beteiligten und daß ,,wichtigere ökonomische Interessen ohne Rücksicht auf einzelne Reiche mit gemeinsamer Kraft und in eigener Regie verfolgt würden". Der polnischen Gesellschaft riet er, ,,gegenüber den Juden nur eine fürsorglich-schützende Haltung einzunehmen und zu wahren"; denn

alles wird vergeblich sein, solange wir nicht, bei Verwerfung der Fehler der Juden, ihre vielen großen Eigenschaften übernehmen und solange nicht auf dem wirtschaftlichen Feld - statt nur Einzelner - die Masse gegen die Masse geht. ${ }^{34}$

Abschließend warnte Jeleński:

bald kann die Zeit kommen, da [ . . ] nicht Juden und Deutsche bei uns, sondern [. . .] wir bei Juden und Deutschen [. . .] leben werden. ${ }^{35}$

Der Ton der Broschüre und die Schlüsse, zu denen Jeleński kam, riefen Proteste der positivistischen Presse, des Izraelita sowie einiger konservativer Organe hervor ${ }^{36}$ Nichtsdestoweniger war dies die erste Schrift des Autors, der ein größerer Erfolg beschieden war - binnen weniger Jahre

${ }^{33}$ Ebd., S. 26.

34 Ebd., S. 69.

35 Ebd., S. 82.

${ }^{36}$ U.a. protestierten Aleksander Świetochowski und Bolesław Prus sowie die Zeitschriften Bluszcz (1877, Nr 44), Tygodnik Ilustrowany $(1878, \mathrm{Nr} 3)$ und Izraelita (1878, Nr 5). In dem letzteren Blatt wurden die Reaktionen der Presse von Peltyn in der Spalte ,Pogadanki" registriert. 
erlebte sie vier Auflagen. Als Antwort auf die Kritik gab Jeleński eine weitere Broschüre heraus, die den Titel ,Höflinge der Juden” trug. ${ }^{37}$ Sie war der nächste Schritt in der Entwicklung seiner Ansichten.

Die Höflinge der Juden fügen der Allgemeinheit ein doppeltes Unrecht zu: zunächst verdunkeln sie die sog. ,,Judenfrage”, denn sie stellen sie auf eine vollkommen verfehlte Grundlage; sodann schwächen sie in der Gesellschaft das Gefühl der eigenen Würde. [. . .]

Die Juden werden uns bestimmt nicht ausbeuten, wenn wir uns nicht ausbeuten lassen. Wenn sie aber niemand haben, den sie ausbeuten können, dann müssen sie sich - in verschiedenen Richtungen - an die Arbeit machen und sich durch die Arbeit sozialisieren. ${ }^{38}$

Eine beliebte Parole Jeleńskis wurde nunmehr die Verdrängung der Juden. Gleichzeitig wurde das Gefühl der von den Juden ausgehenden Bedrohung geradezu zu einer Obsession. Der Feindschaft verdächtigte er alle, die seine phantastischen ökonomischen Theorien kritisierten. Heuchlerisch versichterte er dabei seine Opfer seiner Sympathie.

In allen ihren Schriften bewerfen mich die Herren Juden und ihre Höflinge mit Schmutz, wobei sie mir einen quasi judenfresserischen $\mathrm{Haß}$ vorwerfen, den ich in Wahrheit nie empfunden habe.

Ich kann sogar sagen, daß mir eher viele Eigenschaften (Unternehmungsgeist, Sparsamkeit, Solidarität) des israelischen Volksstamms, die uns leider fehlen, sympathisch sind. ${ }^{39}$

1880 gab Jeleński eine weitere Broschüre im gleichen Stil heraus, die sich diesmal an die Bauern wandte. Er wiederholte darin seine Thesen, bemerkte aber präzisierend:

Nur ein schlechter oder dummer oder sehr ungebildeter Mensch kann die Juden deshalb hassen, weil sie Juden sind und einen anderen Glauben haben [ . . ].

Man darf also die Juden nicht deshalb verachten oder hassen, weil sie Juden sind; aber man muß sich vor ihnen hüten und sich ohne sie zu helfen wissen, weil sie am häufigsten betrügen und von fremder Arbeit leben wollen. ${ }^{40}$

37 J. Jeleński, Dworacy Żydów. Przypisek do kwestyi żydowskiej, Warschau 1878.

38 Ebd., S. 2.

${ }^{39}$ Ebd., S. 10. Peltyn schrieb zu der Broschüre: ,, so ein Haß wächst nicht auf unserem Grund - ein Sohn dieses Landes ist, trotz gelegentlicher Unmutsausbrüche und Streiche, zu systematischem, unerbittlichem Haß gegen seine jüdischen Landsleute nicht fähig"; Jeleński veröffentliche seine utopischen Theorien nur aus Geltungs- und Gewinnsucht. Vgl. P[eltyn], ,,Stowo o nowej broszurze p. J. Jeleńskiego p.t. ,Dworacy Żydów”, in: Izraelita, 1878, $\mathrm{Nr}$ 18, S. 141.

40) Janek Mrówka [J. Jeleński], Narada z Kuba, jakby sobie radzić bez Żydów, Warschau 1880, S. $6 f$. 
Die von Jeleński in seinen vier Broschüren entwickelten Ansichten beschränkten sich auf einen ökonomischen Antisemitismus, dessen Spitze sich - vorzugsweise - gegen die , ungebildeten, fanatischen Massen" sowie die jüdische Plutokratie richtete. Obwohl sie in einem immer agressiveren Ton geschrieben waren, der selbst bei konservativen Publizisten Anstoß erregte, waren die Schlüsse, zu denen er kam, durchaus nicht originell. Ähnliche Ideen verkündeten die Konservativen (z.B. in der Niwa) sowie einige der Positivisten, für die sich die Forderung der Stärkung der ,, Mittelklasse" mit denen der ,,Brechung des jüdischen Monopols" und der ,,Produktivierung" der Juden verband. Alle, die sich an der Diskussion über diese Frage beteiligten, operierten mit ähnlichen Stereotypen, in denen sich eine Abneigung gegen den Handel und die Identifizierung der Juden mit dieser ,,eitlen" Betätigung manifestierten.

Die Anfänge der antisemitischen Bewegung im Königreich waren mit der Gründung des Wochenblatts Rola im Jahr 1883 verknüpft. Die gesellschaftliche und politische Atmosphäre war der Entstehung des Blatts günstig. Die Broschüren Jeleńskis erfreuten sich eines beachtlichen Interesses, judenfeindliche Ausfälle waren in der Publizistik keine Seltenheit mehr. Sie wurden von der Zensur, die die antisemitische Politik der zaristischen Regierung realisierte, nicht behindert. Dennoch wurde die Rola von der Warschauer Presse nicht besonders wohlwollend begrüßt, weder von der positivistischen noch von der konservativen; denn durch den skandallüsternen, lautstarken, verleumderischen Stil seiner Polemik verletzte Jeleński die geltenden Regeln, derart, daß selbst antijüdisch eingestellte Konservative durchaus verärgert reagierten. Außerdem dürften die Leichtigkeit, mit der er die Konzession für das neue Blatt erhielt, und die Übereinstimmung ihres Programms mit der Politik der zaristischen Behörden den Verdacht der anderen Redaktionen erregt haben, die ihrerseits einen dauernden Kampf gegen die Zensur zu führen hatten. Schließlich dürfte eine Rolle gespielt haben, daß die Rola vorzugsweise die Assimilationsbewegung angriff, die in der Presse sonst eher zurückhaltend behandelt wurde. Man zweifelte an ihrem Erfolg, kritisierte ihre ,Mängel”, aber bejahte das Prinzip der Assimilierung selbst. Die meisten der auf ihren Ruf bedachten Journalisten beschuldigten Jeleński, daß er sich unredlicher Methoden bediene, um den Absatz seines Blatts zu fördern. Aber diese Anklage war in den Polemiken nur allzu gebräuchlich, während es doch klar war, daß es kaum ein Blatt gab, dem es nicht auf eine möglichst hohe Leserzahl ankam.

Leider wissen wir zu wenig von Jeleński, um genaueres über seine Persönlichkeit aussagen zu können. ${ }^{41}$ In seinen Arbeiten treten jedoch drei 
Eigenschaften hervor: ein starker, nicht gestillter Ehrgeiz, ein Minderwertigkeitskomplex und ein Mangel an Distanz zu sich und seiner Umwelt. Er war ein Autodidakt mit wissenschaftlichen Ambitionen, dem andere Unwissenheit vorwarfen; er gehörte der szlachta an, war aber viele Jahre gezwungen, sich in subalterner Stellung sein Brot zu verdienen. Es ist denkbar, daß hier eine Quelle mannigfaltiger Frustrationen lag. Auffallend häufig führte er zur Begründung seines Judenhasses den ,,Kampf um die eigene Würde" an. Sich seiner eigenen Komplexe nicht bewußt, projizierte er sie auf naive Weise auf die Juden. Obwohl er durch die Arbeit in der Rola einen Teil seiner Phobien entladen konnte, sprach aus seinen Artikeln das dauernde Gefühl, bedroht zu sein - nicht nur von den Juden, sondern von allen denen, die seine Tätigkeit kritisierten. Es ist aber schwer zu sagen, was dabei individuelle Eigenart, was Element der Taktik der Bewegung war.

Das Programm der Zeitschrift, das in der ersten Nummer abgedruckt war, wurde dreißig Jahre hindurch bis zum Überdruß wiederholt.

Mit der Hilfe, durch den Einfluß unseres Organs wollen wir in möglichst breiten Kreisen der polnischen Gesellschaft eine gewisse Oppositionskraft ausbilden - eine gewisse Partei des beharrlichen legalen Kampfes auf dem wirtschaftlichen Feld [ . . ], wir wollen beharrlich in der einmal festgelegten Richtung voranschreiten, selbst wenn wir bluten müßten von den Dornen auf unserem Weg, selbst wenn wir bei jedem Schritt Schwierigkeiten und Hindernissen begegnen sollten, selbst wenn uns unsere Gegner durch ihren Lärm und ihr Geschrei betäuben wollten. [. . .]

Häufig hörten wir die Ansicht, daß bei uns nur eine große Partei existieren sollte, und im Prinzip stimmen wir dieser Ansicht zu. Wir können jedoch nicht umhin, hinzuzufügen, daß sich diese ,,eine große Partei”, statt sich ihren Idealen zu nähern, vielmehr davon entfernen müßte, wenn auf dem weiten Feld der wirtschaftlichen Aktivität fremde Elemente herrschen, die mit den allgemeinen Zielen nichts gemein haben. [ . . .]

Wir wissen nicht, ob jemand bemerkt hat, daß der Einfluß dieses Stamms, so machtvoll und ausgedehnt, wie er sich gegenwärtig darstellt, hauptsächlich seit dem Moment datiert, da die Gesellschaft auf einmal unter neuen Bedingungen für die Erhaltung des eigenen Daseins zu wirken hatte; andererseits gab die Gleichberechtigung diesem Stamm zweierlei Rechte: außer seinen Kastenrechten - allgemeine [ . . ].

${ }^{41}$ Laut R. Brandstaetter, ,,Obwạchiwanie goja”, in Zmowa eunuchów, Warschau 1936, war er ein Nachkomme von Mojsze Chaskiel Jeleń und seiner Frau Chaja, die im achtzehnten Jahrhundert von dem Priester Turczynowicz (dem Gründer des Klosters der Mariaviten, die die Judenmission betrieben) getauft und danach geadelt worden waren. Aber dieser genealogische Hinweis gibt, soweit er zutrifft, für die Analyse der Persönlichkeit Jeleńskis nicht viel her, zumal nicht bekannt ist, ob er sich eines solchen Herkommens bewußt war. 
Es würde sich endlich auch irren, wer meinte, daß wir die Juden oder Deutschen ,,reizen" wollten, daß wir in der einheimischen Bevölkerung Widerwillen gegen die einen oder anderen entfachen wollten [ . . ]. Wir wiederholen: die Abwehr muß ruhig, legal, systematisch sein. ${ }^{42}$

Das Programm der Rola enthielt eine Reihe politischer Termini: ,Oppositionskraft”, ,Partei” usw., deren Bedeutung unter den damaligen Umständen durchaus klar war; ihr Gebrauch in der Presse, die sie sonst sorgsam mied, stellte ein Novum dar. Jeleński schob indessen, wo er den Ausdruck ,Kampf' benutzte, durchweg sofort das Wort ,legal" ein; außerdem vernebelte er den Gehalt der Termini bis zur Unkenntlichkeit, indem er sie nur in einem ,,gewissen" bzw. ,,bestimmten" Sinn benutzte. Aus derartigen Manipulationen der Begriffe resultierte eine neue Sprache, die wegen ihres militanten Tons einen couragierten, kompromißlosen Ein-. druck machte - während sich die Zeitschrift in Wahrheit der ausgesprochenen Gunst der Zensur erfreute.

In dem programmatischen Artikel der Redaktion offenbarte sich die Sehnsucht nach totalitärer Unterordnung der Gesellschaft unter ein einheitliches Ziel. In der zweiten Nummer machte Jeleński eine Verbeugung nach der Seite der konservativen Großgrundbesitzer.

Keines der sozialen und ökonomischen Probleme ausklammernd, verlieren wir auch nicht einen Moment lang aus dem Auge, was die Grundlage unseres Daseins und vor allem unser kollektives ,,Ich" ausdrückt, nämlich das Grundeigentum. [. . .] Jedermann muß zugeben, daß man kein fanatischer ,,szlachcic" sein muß, um in den Grundeigentümern die wichtigste Klasse der Gesellschaft zu erkennen, sich in ihre Bedürfnisse zu vertiefen und ihre Interessen zu verteidigen. ${ }^{43}$

Allerdings kann man diese Erklärung nicht ganz ernst nehmen. Die politische Botschaft des Blatts war nicht allzu deutlich. Jeleński wandte sich an alle Schichten. Die Rola brachte Artikel über die ,,ländliche Intelligenz", d.h. den Landadel, sie suchte ihre Ideen unter den Bauern, dem Klerus, dem Bürgertum zu propagieren. Sie huldigte dem Adelsstolz, war aber kein konservatives Blatt, war auch kein Sprachrohr der Gutsbesitzer. Ihr eigentlicher Adressat war das Bürgertum, und auf diese Schicht war ihr Quasi-Konservativismus berechnet.

Die Rola focht die Gleichberechtigung der Juden an. Obwohl ihre Redakteure fortgesetzt ihre ,, friedlichen" Absichten betonten, waren ihre Artikel voll von beißenden Invektiven. Das Programm der ,,Verteidigung" gegen , jüdisch-deutsche" Verhältnisse in Polen reduzierte sich de facto auf den ökonomischen Antisemitismus; denn trotz vager Andeutungen inter-

${ }^{42}$ Redakcya, ,Czego chcemy?”, in: Rola, 1883, Nr 1, S. 1f.

${ }^{43}$ Ebd., Nr 2, S. 13. 
essierte sich die Zeitschrift für das deutsche Problem nur wenig. Daraus, daß sie hinsichtlich der Assimilierung der Juden Zweifel hegte, machte die Rola von Anfang an nicht den geringsten Hehl. So ereiferte sich etwa Jeske-Choiński:

ich glaube nicht an eine Assimilierung der Semiten, ihr Aufgehen in den Nationen, unter denen sie leben, solange sie an dem mosaischen Bekenntnis festhalten. Der semitische Charakter, der überdies auf eine sehr subtile Weise durch ein jahrhundertelanges Herumwandern und Schachern geprägt ist, unterscheidet sich zu sehr von unserem, als daß wir uns einfach so, auf Wunsch einiger Journalisten, verschmelzen könnten. Nur durch die Mischung von Blut mit Blut, nur durch den Verzicht auf den mosaischen Glauben und den Talmud könnten mit der Zeit die rassisch-religiösen Unterschiede verschwinden [. . .]. Alle ,Assimilationen" sind unter den gegenwärtigen Bedingungen einfach eine Utopie von unserer Seite und eine Täuschung von der Seite der Juden [ . . ]. Widerlich ist uns der sog. , ,zivilisierte" Jude, der an nichts glaubt außer Gold und sinnlichen Genuß [ . . ].

Bist du ein Jude, dann sei es! Der unaufgeklärte orthodoxe Jude ist uns lieber als die zivilisierte Null; denn der erstere glaubt an etwas, ist etwas, der letztere aber bietet keinerlei Gewähr. Um des Geschäftes willen verkauft, verhökert er alles, da er ein Anhänger eines rücksichtslosen, gemeinen Utilitarismus ist. ${ }^{44}$

Derartige Angriffe wurden, im Lauf der Jahre um neue Vorwürfe bereichert, unaufhörlich wiederholt.

Die Assimilierten beschuldigte die Rola eines negativen Einflusses in allen Lebensbereichen. In der Politik verdrängten sie das adlige Kolorit durch die ,farblose Gräue" des Liberalismus; in das gesellschaftliche Leben brachten sie ,,Zynismus, Atheismus, religiöse Indifferenz, Geringschätzung für Ideale und für geistige Güter, Verhimmelung der materiellen Mittel und des Goldes, Servilität und Karrierismus"; die jüdischen Publizisten verbreiteten ,,Spekulation, Terrorismus gegenüber anderen Überzeugungen” sowie ,,Realismus in Kunst und Literatur"; die jüdischen Advokaten förderten ,,Prozeßsucht und Schwindel”; die jüdischen Ärzte betrachteten ihren Beruf als ein ,,gewöhnliches Gewerbe". ${ }^{45}$ Paradoxerweise demonstrierte das Blatt eine fast übernatürliche Macht der bewußten Gruppe, die allem, was sie anrührte, ihr Siegel aufprägte.

Das positive Programm des Blatts war ausgesprochen dürftig. Es ging nur wenig über das hinaus, das Jeleński bereits in seinen Broschüren lanciert hatte. Die Rola propagierte verschiedene Formen der ,,Verdrängung”' der Juden, vor allem ihre Verdrängung aus dem Wirtschaftsleben

44 Pancerny [T. Jeske-Choiński], , Na posterunku”, ebd., 1883, Nr 19, S. 8 f.

45 J. Jeleński, ,Najgroźniejsi”, ebd., 1885, Nr 12, S. $133 f$. 
des Landes. Dazu schlug das Blatt die Gründung von Genossenschaften vor, die Organisierung billigen Kredits zur Bekämpfung des Wuchers, endlich - den Boykott des , jüdischen" Handels. ${ }^{46}$ Weiterhin empfahl die Rola, die Assimilierten aus dem gesellschaftlichen Leben zu verdrängen. ${ }^{47}$ So sprach sie sich in den neunziger Jahren gegen gemeinsame Ferienlager für polnische und jüdische Kinder aus. ${ }^{48}$ Schon 1884 rief sie zur Beschränkung der Zahl der jüdischen Kinder in den Schulen auf. ${ }^{49}$ Außerdem brachte das Blatt einschlägige Nachrichten aus dem täglichen Leben: z.B. schrieb es über eine polnische Lehrerin, die ihre Stellung bei einer jüdischen Familie gekündigt hatte, weil man ihr bei Tisch zuletzt serviert hatte, wodurch man sie ,,als Gast, als Frau, als gesellschaftlich und moralisch Höherstehende beleidigt hatte". ${ }^{50}$ Jeleński protestierte gegen die Teilnahme von Juden an kirchlichen Trauungsfeierlichkeiten und verurteilte die Annahme eines Hochzeitsgeschenks ,,vom Juden" durch das Brautpaar. ${ }^{51}$ Um die , Reinheit" des Handwerks kämpfend, sprach er sich dagegen aus, daß christliche Meister jüdische Gesellen einstellten bzw. christliche Jungen bei jüdischen Meistern in die Lehre gingen. ${ }^{52}$

Segregierung und Diskriminierung propagierend, engte das Blatt den Kreis der Assimilierten, die man notfalls tolerieren konnte, immer weiter ein. Zunächst waren das nicht näher definierte ,löbliche Ausnahmen"; 1884 wurde die Taufe der Assimilierten empfohlen; $;^{53}$ danach wurden die Neophyten angegriffen. Man protestierte gegen Mischehen und die Annahme polonisierter Namen. ${ }^{54}$ Schon im zweiten Jahr ihres Bestehens

46 J. J[eleński], ,Uczciwe zmowy”, ebd., 1883, Nr 3; Pancerny, , Na posterunku”, ebd., 1883, Nr 17; ,,Z Końsko-Woli (wzorowy czyn)”, ebd., 1885, Nr 35; ,Najpewniejsza obrona", ebd., 1885, Nr 43; , ,Z Końsko-Woli (nowe fakta)", ebd., 1885, Nr 48.

${ }^{47}$ Vgl. u.a. , Na dzisiaj”, ebd., 1884, Nr 20; , ,Judaica”, ebd., 1886, Nr 5.

48 Kamienny [J. Jeleński] zitierte in seinem Artikel , Na posterunku”, ebd., 1893, Nr 14, S. 234, den Brief einer Leserin, in dem es hieß: ,Ich gehöre durchaus nicht zu den erbitterten ,Fressern' der Söhne Israels - und ich habe nichts dagegen, daß jüdische Kinder ebenfalls an Ferienlagern teilnehmen; denn schlieBlich sind das auch menschliche Wesen; aber den Anhängern der sog. ,Assimilation' würde ich mich - die Folgen im praktischen Leben deutlich sehend - nie anschließen. Nicht die Juden ,assimilieren sich' uns, sondern wir nehmen eher ihre Eigenschaften an, vor allem aber ihre judaistische Ethik, die zu der unseren, christlichen in einem derart prinzipiellen Gegensatz steht." Dieser Brief leitete eine langdauernde Kampagne der Zeitschrift ein. Vgl. u.a. ,,Kronika bieżaca", ebd., 1893, Nr 28, 33, 38.

49 ,Judaica, Żydzi w szkolach", ebd., 1884, Nr 25.

50 ,Kronika bieżaca”, ebd., 1891, Nr 46, S. 781.

51 Kamienny, ,Na posterunku', ebd., 1893, Nr 45.

52 U.a. ,Kronika bieżąca (Także asymilacya!)”, ebd., 1893, Nr 37.

53 J. Jeleński, , Co to znaczy?", ebd., 1884, Nr 30; Swojak, , Historyk o Żydach”, ebd., 1897, Nr 6.

${ }^{54}$ S. Godlewski, ,,Uspołecznieni”, , ebd., 1891, Nr 24; T. Jeske-Choiński, ,,Z literatury 
begann die Rola eine extreme Form der Verdrängung der Juden zu propagieren-ihre Auswanderung. ${ }^{55}$ Außerdem schlug sie zaghaft die Aufhebung des ,,Ansiedlungsrayons" vor. ${ }^{56}$

Im ersten Jahr seines Bestehens verwahrte sich das Blatt noch gegen das Epitheton ,,antisemitisch"; zugleich betonte es, daß es den Kampf im Einklang mit der ,,christlichen Ethik" zu führen wünsche. Aber schon ein Jahr später bediente es sich selbst jener Bezeichnung, ${ }^{57}$ wobei es die Entstehung der Feindschaft gegen die Juden mit ihrer Gleichberechtigung verband: „Bevor die Juden die Bürgerrechte erhielten, konnte von Antisemitismus im heutigen Sinn keine Rede sein." ${ }^{58}$ Gleichzeitig wurde das Bekenntnis zu den Grundsätzen der ,,christlichen Ethik" immer zweifelhafter - und seltener. Die Rola applaudierte den Pogromen ${ }^{59}$ und den Ritualmord-Prozessen. ${ }^{60}$ Es tauchten immer neue aus der antisemitischen Publizistik Westeuropas übernommene Elemente auf. Als besonders ,,dankbar" erwiesen sich die Vorwürfe, die Juden hätten einen maßgeblichen Anteil an der ,Freimaurerei"'61 und an der sozialistischen Bewegung. ${ }^{62}$ Beide Motive spielten eine zentrale Rolle in der antisemitischen Mythologie des zwanzigsten Jahrhunderts. Die Rola entwickelte sie noch recht schüchtern, als ahnte sie die Möglichkeiten, die sie bargen, ohne sie bereits voll ausschöpfen zu können.

Die Rola war das erste Blatt im Königreich, das sich moderner Agitationsmethoden bediente, die den anderen Organen bis dahin fremd waren. Es scheint lohnend, die Entwicklung der Methoden, die Jeleński und seine Freunde selber erst erlernten, näher zu betrachten. Besonders aufschlußreich in dieser Hinsicht ist die Übersicht über die einzelnen Jahrgänge in

scenicznej. Komedye żydowskie p. Kazimierza Zalewskiego", ebd., 1887, Nr 30; Hreczkosiej, , ,Hreczkosiej do Magnatów”, ebd., 1885, Nr 29; Kamienny, ,,Na posterunku”, ebd., $1887, \mathrm{Nr} 44$.

55 ,,Emigracya”, ebd., 1884, Nr 24.

56 ,Warszawa dnia I sierpnia", ebd., 1885, Nr 31.

57 ,Uzasadnienie antisemityzmu”, ebd., 1884, $\mathrm{Nr}$ 15-17.

58 "Antysemityzm jako wyraz czasu", ebd., 1890, Nr 43, S. 713.

59 ,Kronika bieżaca”, ebd., 1884, Nr 20.

60 ,Judaica. Sprawa Ritterów”, ebd., 1885, Nr 39. Das Blatt verhehlte nicht seinen Glauben an den Ritualmord und attackierte die Angeklagten.

61 B. Szczerbiec, ,,Bezwyznaniowość i Żydzi”, ebd., 1890, Nr 11. Das ganze Jahr 1896 hindurch (Nr 1-51) brachte die Rola eine sensationelle Serie von Artikeln zum Thema der Freimaurerei (A. Lemma, „Najwyższy wódz masonów”; D. Margiotto, ,,Kult szatana"), die vom Przegląd Katolicki, 1896, Nr 44, als Phantasterei entlarvt wurde, worauf die Rola, 1896, $\mathrm{Nr} 45,48,51$, scharf gegen jenes Blatt polemisierte.

62 ,,Kronika bieżaca”, ebd., 1893, Nr 50; Lechita, , ,Z Nowej Judei (Żydzi-socyaliści)”, ebd., 1897, Nr 14-15; Kamienny, ,,Na posterunku”, ebd., 1897, Nr 37. 
dem Gedenkbuch aus Anlaß des fünfundzwanzigjährigen Bestehens des Blatts.

Im ersten Jahrgang treten gleich das Programm und der Kurs hervor, denen die Rola das ganze Vierteljahrhundert hindurch huldigte. Naturgemäß haben die einleitenden Artikel des ersten Jahrgangs einen programmatischpädagogischen Charakter, derart, daß sie den Lesern das klar und deutlich formulierte Isolierungsprogramm in der Judenfrage, das in der polnischen Publizistik bis dahin nicht bekannt war, nahebringen sollten. Die konservative Orientierung des Blatts zeichnet sich nachdrücklich und klar in der Polemik mit den Organen der liberal-konfessionslosen Presse ab. Überhaupt ist der polemische Ton, der der Rola ihre besondere Stellung innerhalb der Warschauer Presse gibt, in allen Artikeln zu sozialen Fragen zu erkennen. Viel Platz wurde im ersten Jahrgang den Angelegenheiten der Gutsbesitzer eingeräumt, nicht weniger der Verteidigung des Standes der Gutsbesitzer gegen die Angriffe der ,Progressiven”. Jedenfalls hat der Konservativismus der Rola eine durchaus demokratische Grundlage. ${ }^{63}$

Verschiedene Autoren heben die Monotonie hervor, die der gesamten Literatur dieses Typs gemeinsam war. ,,One of the striking features of antiSemitic literature", schrieb Vamberto Morais, ,, is the poverty of its imagination, the dull, strip-cartoon character of its products." ${ }^{64}$ Die im neunzehnten Jahrhundert aufkommende Bewegung suchte ihre Publizistik dem Geschmack der Massen anzupassen. Was das betraf, ging die Rola im Königreich zweifellos voran. Die Presse richtete sich dort an die ,, aufgeklärte öffentliche Meinung". Auf ihre besondere Rolle in der Zeit nach 1863-64, ihren Sendungsglauben war zurückzuführen, daß sie nur ausgewählte Kreise der Gesellschaft anzusprechen suchte, wobei sie einen gewissen Stil, gewisse ungeschriebene Regeln ausbildete. Die Rola durchbrach diese Konventionen. Sie bevorzugte einen aggressiven Ton, vereinfachte bewußt die Wirklichkeit, bediente sich des Mittels der Verleumdung. Auch daß sie nie die Namen angegriffener Personen wegließ, erregte Anstoß, zumal die Zensur dafür sorgte, daß die Angegriffenen sich nicht wehren konnten. Deshalb wurde auch Kritik der Rola vorzugsweise jenseits der Grenzen - in Galizien - publiziert, worauf Jeleński selbst hinwies.

Statt dessen bediente man sich eines bereits mehrfach erprobten Mittels: einer jenseits der Grenzen herausgegebenen und später heimlich verbreiteten Schmähschrift. Doch ging diesmal der beabsichtigte Schlag fehl, zumal die Rola die wahre Physiognomie des sich hinter einem Pseudonym verbergenden Autors der Schrift aufdeckte. Es handelte sich um einen gewissen Finkelhaus, einen Warschauer Anwalt und Mitarbeiter konfessionslosjüdischer Organe. Dieser Finkelhaus kam wenig später in Konflikt

${ }_{63}^{63}$ Ćwierćwiecze walki. Ksiega pamiatkowa ,,Roli”, Warschau 1910, S. 106.

${ }_{64}$ V. Morais, A Short History of Anti-Semitism, New York 1976, S. 197. 
mit der geltenden Moral und dem geltenden Recht und verlor den Titel eines vereidigten Anwalts, wonach er schnell nach Paris übersiedelte, wo er sich nach Änderung seines Namens in einen französischen Literaten umstilisierte. ${ }^{65}$

Jeleński ,,vergaß" hinzuzufügen, daß jener Konflikt mit dem geltenden Recht erst eine Folge seiner eigenen Denunziation war. Die Rola denunzierte nämlich gerne. In dem erwähnten Gedenkbuch hieß es prahlerisch:

In diesem Jahr [1891] entstand in konfessionslos-jüdischen Kreisen der Plan der Bildung irgendeines Warschauer Journalisten-Syndikats zur Vernichtung des Einflusses des wahrheitsliebenden Blatts. Ein Artikel der Rola unter dem Titel ,,Die Würde der Presse”, der die Intrigen hinter den Kulissen aufdeckte, vereitelte das abgekartete Spiel. ${ }^{66}$

Die zitierte Passage bezog sich auf die von den Positivisten - Eliza Orzeszkowa, Aleksander Świętochowski u.a. - geplante Gründung der Verlagsgenossenschaft Światto. Vereitelt wurde sie durch die Zensur. 1891 strengte Jeleński ferner gegen den Redakteur der neuen Zeitschrift Ziarno einen Prozeß wegen übler Nachrede an, den er gewann. Das Gedenkbuch hierzu:

In dem kurz vorher gegründeten in Warschau erscheinenden Blättchen, das den Namen Ziarno trug, erschien ein Artikel unter dem Titel, ,Ein Antisemit", der nicht nur gegen die Rola gerichtet war, sondern zugleich die Ehre und den guten Namen ihres Redakteurs besudelte. Der Inhalt des Artikels machte jede - sei es noch so scharfe - Polemik unmöglich. Es blieb daher nichts anderes übrig, als den Redakteur und Herausgeber des Ziarno, Herrn Kazimierz Korwin-Piotrowski, vor die Schranken des Gerichts zu ziehen. In $\mathrm{Nr} 47$ des Jahrgangs ist der Verlauf der Verhandlung und ihr Schluß in Gestalt der Verurteilung des Redakteurs des Ziarno zu einer Gefängnisstrafe ausführlich besprochen. ${ }^{67}$

Das Blatt schwelgte in Skandalen und Sensationen, die es häufig selbst ersann. Nichtigkeiten blähte es zu Fragen von fundamentaler Bedeutung auf; die fehlende Bedeutung des Gegenstands kompensierte es durch hartnäckige Ausdauer in seiner Behandlung. Die Rola führte im Königreich das, was später ,Pressekampagne" genannt wurde, ein, d.h. behandelte gewisse Themen über einen längeren Zeitraum, manchmal mehrere Jahrgänge hinweg, immer von neuem auf zermürbend monotone Weise. Gleichzeitig bemühte sie sich um eingängige Parolen wie z.B. ,Brot für unsere eigenen Leute". Die entsprechende Aktion begann die Rola 1885,

65 Ćwierćwiecze walki, a.a.O., S. 117.

to Ebd., S. 118.

${ }^{67}$ Ebd. 
wobei es um eine Neuauflage des ökonomischen Programms ging, das Jeleński schon seit vielen Jahren propagierte.

Die ,Kampagnen" füllten bald beinah das ganze Blatt. 1892 waren es gleich vier auf einmal: eine gegen die ,Anzeigen-Korruption" des Kurier Warszawski (es ging um den Heiratsanzeigen-Teil); eine, die die ,Frage des Almosensammelns" betraf (sie war ausgelöst durch Klagen eines Priesters über das , ungebührliche Verhalten gewisser almosensammelnder Damen", die am Karfreitag für die Armen gesammelt hatten); eine gegen gemeinsame Sommerlager für jüdische und christliche Kinder; eine, die einen Streit um die Eigentumsrechte an der Handwerksschule betraf. Dazu kamen noch einige kleinere Kampagnen.

Außer dem mehr der Selbstverteidigung als dem Angriff dienenden dauernden intensiven Kampf mit dem übermächtigen Judentum und seinem Anhang: den atheistischen Liberalen, außer der kontinuierlichen Entwicklung der Rubrik ,Brot für unsere eigenen Leute" gilt es in diesem Jahrgang auf das Anprangern des Sinekurismus der Berater der Landwirtschaftlichen Kreditgesellschaft hinzuweisen, die zum Schaden der elementarsten Interessen dieser Institution der Gutsbesitzer zugleich gutbezahlte Posten in den spekulierenden, vorzugsweise unter dem Einfluß semitischer Financiers stehenden Versicherungsgesellschaften bekleiden. ${ }^{68}$

Bei der Durchsicht der Zusammenfassungen der einzelnen Jahrgänge der Rola in dem Gedenkbuch entsteht der Eindruck, als sei das Blatt vollkommen isoliert gewesen, fast von der ganzen öffentlichen Meinung abgelehnt und boykottiert. Ständig mußte es auf die Attacken anderer Organe reagieren - sowohl positivistischer als auch konservativer. 1886 war es in eine Polemik mit dem Przeglad Tygodniowy und der Prawda verwickelt, die es besonders gern angriff, da für seine Redakteure ,,liberal-atheistische Elemente" eben Juden waren. Anderen Blättern - so dem Warschauer Glos, dem Krakauer Czas und dem Petersburger Kraj-warf die Rola vor, daß sie dem Einfluß jener unterlägen. ${ }^{69}$ Den gleichen Vorwurf machte sie T. T. Jeż (Zymunt Milkowski), der zunächst selbst in der Rola publiziert hatte. ${ }^{70} 1889$ gab es eine Kontroverse mit dem Kurier Codzienny und Bolestaw Prus. 1893 konzentrierten sich die Angriffe auf die Niwa, in den Jahren danach auf das Stowo. ${ }^{71}$ Die Rola fühlte sich selbst durch den Przeglad Katolicki bedrängt, dem gegenüber sie neutral zu

68 Ebd., S. 119-21.

${ }_{69}$ Ebd., S. 110.

70 Ebd., S. 115; T. T. Jeż hatte in der Rola, 1883, Nr 1-5, 21-30, 50-52, eine Serie von Artikeln publiziert, sich aber, nachdem er sich über den Charakter der neuen Zeitschrift orientiert hatte, zurückgezogen.

71 Ćwierćwiecze walki, S. $123 \mathrm{f}$. 
bleiben wünschte. ${ }^{72}$ Obwohl in der Betonung des einsamen Kampfes der Rola viel Prahlerei war, war sie unter den polnischen Blättern tatsächlich lange Zeit eine Art schwarzes Schaf. Jeleński klagte 1887, daß die Warschauer Cafés das Blatt nicht abonnieren wollten. Er berichtete auch über Flugblätter, die zum Boykott aufriefen. Noch einige Jahre später stellte er voll Zorn fest, daß die Mehrzahl der Warschauer Blätter ablehnten, die Rola anzuzeigen. ${ }^{73}$

Allerdings war das Bild der öffentlichen Meinung des Königreichs, das die Rola gab, geschönt. Wenn man selbst die Warschauer Presse durchsieht, findet man nicht ohne Mühe jene Angriffe, die im Gedenkbuch so gewissenhaft verzeichnet wurden. Die Mehrzahl der Zeitschriften, die Jeleński 1883 noch verspottet hatten, wahrten später Stillschweigen. Zwar kritisierten sie sporadisch seine verschiedenen Kampagnen, Denunziationen etc.; aber diese Fragen wurden kaum je auf der Frontseite erörtert. Wenn die Autoren des Gedenkbuchs nichtsdestoweniger den Eindruck zu erzeugen suchten, daß die Rola allseits von Feinden - bemerkenswerterweise nicht nur Juden - umgeben war, könnte man daher geneigt sein, darin eine Art Verfolgungswahn zu sehen. In Wahrheit gehörte diese Beschwörung einer allgegenwärtigen Bedrohung zu einer Taktik, die indessen erst von anderen später voll entwickelt wurde.

Der Ausgangspunkt der Rola war ein ökonomischer Antisemitismus. So primitiv, so unhaltbar Jeleńskis Theorien sein mochten, sie resultierten immer noch aus rationalem Denken, dem Bemühen um Erkenntnis. Aber im Verlauf der Ausbildung der neuen Agitationsmethoden wurden die propagierten Thesen immer irrationaler. Dem entsprach der Stil, den das Blatt entwickelte. Die Sprache war unscharf, aber reich an pseudowissenschaftlichen ,Fach"-Ausdrücken. Es war eine Neu-Sprache, die sich durch einen übermäßigen Gebrauch von allen möglichen Epitheta auszeichnete. Es war nicht immer einfach, in dem Wortschwall zu erkennen, was gemeint war. Desto leichter waren die unkritischen Leser, an die sich die Rola richtete, manipulierbar. Die Zeitschrift bediente sich des Stils der Groschen-Literatur, in dem aber zugleich etwas war, was man ,,magischen Szientismus" nennen könnte. Sie befriedigte so die wissenschaftlichen Aspirationen eines halbgebildeten Publikums, das sie zugleich in seinen Vorurteilen bestärkte. Ein ,,seriöses" Blatt bestätigte gleichsam all das, was andere Journalisten kurzerhand als Aberglauben abtaten.

Zwar operierte die Rola im neunzehnten Jahrhundert noch nicht mit dem völlig irrationalen Mythos von dem ,Hauptfeind", aber sie tendierte schon in diese Richtung, wobei sei eine beachtliche Intuition bewies. Sie 
griff auf die ethnozentrische Tradition zurück (z.B. wenn sie suggerierte, daß die ,,Ritualmord"'-Vorwürfe begründet waren), auf religiöse Motive (z.B. wenn sie die Überlegenheit der christlichen Ethik nachwies), soziale (wenn sie den Juden vorwarf, daß sie die anerkannte Ordnung der Gesellschaft untergruben), ökonomische, nationale (wenn sie über die ,Verjudung" Polens klagte) und politische. Alle diese Motive kumulierten und vermengten sich, wobei der Jude immer deutlicher zu dem Symbol für alles Schlechte wurde. ${ }^{74}$ Hertz bemerkte hierzu:

Ein geschlossenes, sehr stabiles und nicht bedrohtes Milieu behandelt den Fremden, selbst wenn es ihn ablehnt, nie so hysterisch wie ein in sich zerstrittenes und seiner Werte ungewisses [...].

Die Aversion gegen die Juden nahm zu, als sich objektiv die jüdische Gruppe der polnischen anglich [ . . ]; dazu kommt es, wenn die sich assimilierende Gruppe ,,aus der Rolle fällt", nämlich aufhört sich so zu verhalten, wie man es von ihr erwartet, vielmehr sich dem traditionellen, verfestigten Stereotyp entgegenstellt. ${ }^{75}$

Hertz fügte hier hinzu, daß der $\mathrm{Ha} ß$ bei den Schichten am stärksten war, die den Verlust des - wenngleich geringen - gesellschaftlichen Prestiges, dessen sie sich bis dahin erfreut hatten, befürchten mußten.

Die letzteren Bemerkungen leiten über zur politisch-sozialen Dimension des Antisemitismus. Durchaus treffend ist die Feststellung von Jacek Kuroń, daß jene Bewegung den größten Erfolg dann hatte, wenn die Gesellschaft ihrer Handlungsfreiheit beraubt war. ${ }^{76}$ Die des Königreichs erfreute sich Ende des neunzehten Jahrhunderts gewiß keines Übermaßes. Durch die ökonomischen Probleme wurde ihre Lage zusätzlich erschwert. Ein günstigerer Nährboden für ethnische Konflikte war kaum denkbar. Dabei diente der Judenhaß, den die Rola repräsentierte, keineswegs der Erhal-

${ }^{74}$ Der Mythos von dem Juden als allgegenwärtigem Feind spielte erst im Antisemitismus des zwanzigsten Jahrhunderts eine zentrale Rolle. Einen besonders krassen Ausdruck fand er in den berüchtigten, von einem Ochrana-Agenten verfaßten ,Protokollen der Weisen von Zion", die in den zwanziger Jahren internationale Popularität erlangten. Auch heute kann man diesem Mythos noch begegnen. So meinte eine Frau aus Strzyżów, die ich im Rahmen der Vorbereitung meiner Magisterarbeit interviewte, in einem Atemzug, die Juden hätten Christus ermordet, Christenblut für die Matze benutzt, Szela bestochen, daß er die szlachta ermorden ließe, den Januaraufstand erst angezettelt, dann seinen Zusammenbruch herbeigeführt und endlich die Oktoberrevolution hervorgerufen, wodurch sie den Bolschewismus über Polen gebracht hätten. Zwischendurch hätten sie, Handel treibend, ein faules Schwindlerleben geführt. Vgl. A. Cala, ,,Obraz kultury żydowskiej w polskiej kulturze ludowej”, mschr. Ms., Magisterarbeit Warschau 1977.

${ }^{75}$ Hertz, Żydzi w kulturze polskiej, a.a.O., S. 114.

76 Äußerung von J. Kuroń während einer im März 1981 an der Warschauer Universität abgehaltenen Konferenz über die Ereignisse vom März 1968. 
tung der bestehenden Ordung. Das Blatt bezeichnete sich selbst als, ,konservativ auf durchaus demokratischer Basis" ${ }^{77}$ bzw. wenige Jahre später als ,,demokratisch bei durchaus konservativer Orientierung", ${ }^{78}$ wobei es sich nicht nur um eitle Koketterie von Seiten Jeleńskis handelte. Vielmehr entsprachen diese Bezeichnungen der Definition des Nationalismus, die Stanislaw Ossowski gab. Laut Ossowski war derselbe ,,die Synthese zweier gegensätzlicher Tendenzen: der alten antinationalen, konservativen Staatsideologie und der staatsfeindlichen, revolutionären nationalen Ideologie", wobei sich seine Spitze nach außen richtete. ${ }^{79}$ Die Rola war zugleich konservativ und modernistisch, zugleich national und loyalistisch - letzteres bis hin zur Servilität, z.B. wenn sie denunzierte oder Prozesse anspannte, die zu gewinnen sie von vornherein gewiß sein konnte.

Der Kreis um Jeleński bekannte sich zu einem reinen, emotionalen Antisemitismus, der in seiner Neuheit bald von anderen Gruppen entdeckt wurde. 1886 verließ Jan Ludwik Poptawski die Prawda, um den Glos zu gründen. Die neue Zeitschrift, die radikalen Grundsätzen huldigte, die denen des russischen Narodničestvo verwandt waren, nahm beinahe von Anfang an den Juden gegenüber eine ablehnende Haltung ein. In der dritten Nummer erschien ein Artikel Henryk Nusbaums, in dem dieser den Standpunt eines Polen mosaischen Glaubens in einer der Assimilationsbewegung so ungünstigen Zeit begründete ${ }^{80}$ Poptawski antwortete hierauf in der nächsten Nummer in einen Artikel über ,,Antisemitismus und Judenfrage", in dem er meinte, daß der Hauptgrund der Abneigung gegen die Juden in ihrer Andersartigkeit liege, aber präzisierend hinzufügte, daß das für das Verhältnis der ,,Masse” beider Gruppen, nicht aber die Intelligenz gelte.

Heute aber, da die Nationalität die wichtigste Grundlage für die Gesellschaftsbildung ist, da sich das Gefühl der Stammeseigenart gewaltig verstärkt hat, mußte eine Reaktion gegen ein Element eintreten, das sich dem Streben nach Einheitlichkeit verbissen widersetzt. Die moderne antijüdische Bewegung ist ohne Zweifel ein patriotischer Prozeß, der dem vollkommen analog ist, zu dem es im menschlichen Organismus kommt, wenn irgendein fremder Körper in ihm steckt. ${ }^{81}$

Gegen diese Ausführungen, die sich auch auf die Assimilierten bezogen, protestierte der Izraelita:

${ }_{77}$ Cwierćwiecze walki, S. 106.

78 Ebd., S. 110.

79 S. Ossowski, Dziela, Bd 3, Warschau 1967, S. 244.

${ }^{80} \mathrm{H}$. Nusbaum, , ,Jestem żydem - dlaczego", in: Glos, 1886, Nr 3.

${ }^{81}$ Redakcja [J.L. Poptawski], ,,Antysemityzm i sprawa żydowska”, ebd., 1886, Nr 4, S. 51 . 
Sollte es schließlich unmöglich sein, die Disharmonie, die die Andersartigkeit der Juden hervorruft, zu beseitigen? [. . .] Wo ist denn diese soziale Harmonie in den Sphären der ,,Einheimischen" ${ }^{82}$

Davon ausgehend daß die Judenfrage einen religiösen, einen ,,Stammes”und einen ,,sozio-ökonomischen" Aspekt habe, sprach sich Poplawski für die ,staatsbürgerliche Assimilierung" aus, d.h. die Form der Assimilierung, die die Polen mosaischen Glaubens repräsentierten. Allerdings zweifelte er daran, daß sie bald eintreten und viel nützen würde:

jede Gesellschaft muß in ihrem Verhältnis zu den Juden nach ihrer Vernichtung streben - ob diese Ausrottung, Ausstoßung oder Assimilation genannt wird, ändert nichts am Wesen der Sache. Sowohl die Judophilen als auch die Antisemiten wollen die Juden qua Juden vernichten, d.h. qua Vertreter einer besonderen Gemeinschaft [. . . ].

Angesichts der religiösen Differenzen kann sich die jüdische Bevölkerung stammesmäßig der polnischen noch nicht bald assimilieren; wenn diese Assimilierung aber möglich wäre - wer weiß, ob sie erwünscht wäre. In dieser Frage steht das letzte Urteil der Anthropologie zu [. . .].

Was aber die Taufe eines beträchtlichen Teils der jüdischen Intelligenz betrifft, würde ich sie, wenn sie wirklich möglich wäre, gegenwärtig für außerordentlich schädlich halten. ${ }^{83}$

In dem Artikel Poplawskis kündete sich so bereits der rassistische Antisemitismus an.

Theorien über einen Zusammenhang zwischen psychischen Merkmalen und anthropologischer Konstitution tauchten in den Randzonen der Wissenschaft bereits im achtzehnten Jahrhundert auf. Es handelte sich aber immer nur um Hypothesen. In der zweiten Hälfte des neunzehnten Jahrhunderts wuchs ihre Popularität, wobei sich Vertreter verschiedener Konzeptionen - einschließlich der Befürworter der Assimilierung - auf sie beriefen. Gegen Ende des Jahrhunderts aber nahmen sie zunehmend den Charakter einer Ideologie an und bewegten seither viele Geister. Jene rassistischen Theorien ermöglichten einem beträchtlichen Teil der Intelligenz, sich ohne Skrupel, dadurch in Gegensatz zur wissenschaftlichen Erkenntnis bzw. zum gesunden Menschenverstand zu geraten, zum Antisemitismus zu bekennen. Der Glos war das erste Blatt im Königreich, das diesen intellektualisierten Antisemitismus kolportierte. Derselbe richtete sich in erster Linie gegen die Assimilierten. Ein Autor, der sich über dieses Thema in besonders drastischen Formulierungen ausließ, schrieb:

Da sind zwei Organismen; in dem einen davon steckt statt eines eigenen

82 P[eltyn], ,Inni”, in: Izraelita, 1886, Nr 42, S. 338.

${ }^{83}$ Redakcja [J. L. Poplawski], .,Antysemityzm i sprawa żydowska”, a.a.O., S. 5 lf. 
[. . .] Organs ein fremdes; in dem anderen aber haben sich fast sämtliche Organe zu einem einzigen amorphen Agglomerat verschmolzen, das, schmarotzerhaft, in seiner Entwicklung gehemmt, sich nur entfalten kann um den Preis des Verlusts der eigenen Individualität bzw. um den Preis eines gewissen politischen ,Mimikri”, d.h. derart, daß es das Äußere anderer Systeme annimmt.

Im Namen ,,allgemeinmenschlicher Ideale und Gefühle" wies er auf die „,außerordentliche Schädlichkeit der Juden" hin und protestierte gegen ihre Assimilation.

Unter den bisher vorgeschlagenen Remedien nimmt den ersten Platz die sog. Assimilierung ein. Es ist das im Grunde ein aristokratisches Programm, das weder die große Zahl noch die Lage noch die Interessen der jüdischen Massen berücksichtigt, andererseits aber auch nicht die Assimilationskraft der polnischen Bevölkerung in Betracht zieht [. . .]. Es ließe sich viel über die Schädlichkeit bzw. Nützlichkeit der Assimilation sagen, wenn es nicht so wäre, daß uns ihre völlige Unmöglichkeit - ohne das Mittel des Zwangs diese akademischen Erörterungen erspart. Hier also muß nur die Schädlichkeit nicht der Assimilation selbst, sondern des hier und da auftauchenden Assimilationsprogramms für die Gesellschaft hervorgehoben werden. Nicht alle Illusionen sind schädlich; aber diese ist es ohne Zweifel; sie hemmt vor allem die autonome Zivilisationsarbeit der intelligenten Juden, macht die polnischen Optimisten blind für das brutale, harte Faktum der feindlichen Besonderheit der Juden, verhindert eine angemessene Beurteilung all ihrer Folgen. ${ }^{84}$

Abschließend empfahl er die Emigration der Juden.

$\mathrm{Zu}$ ähnlichen Schlüssen gelangte Witold Ziemiński. Er verwarf den Grundsatz der Assimilierung, die er für ein Hirngespenst hielt, und erklärte, daß die jüdische Frage erst in einer, ,genossenschaftlichen" Verfassung lösbar werde. Einstweilen empfahl er eine Förderung des einheimischen Handels und der einheimischen Industrie, bemerkte aber, daß sich das Problem nicht ausschließlich auf ökonomische Aspekte reduzieren lasse. Die Juden würden sich stets vorzugsweise um die eigenen Interessen kümmern, sie seien nämlich eine besondere Nation und würden in der polnischen Gesellschaft immer zum ,,Wallenrodismus" ${ }^{85}$ neigen. In Polen ,,sei kein Platz" für zwei verschiedene Nationalitäten, ihr Zusammenleben würde immer zu Konflikten führen. Deshalb hielt auch er die Assimilie-

\footnotetext{
${ }^{84}$ J. K. Potocki, ,Antysemityzm ,Glosu”, in: Glos, 1891, Nr 4-8, S. 39, 85.

85 Anmerkung des Übersetzers: nach Konrad Wallenrod, dem Helden des gleichnamigen Werkes von Adam Mickiewicz: ein litauischer Junge, der von den Kreuzrittern zu einem der ihren erzogen wird, aber im Herzen seinem Volk treu bleibt, steigt unter jenem Namen zum Großmeister des Ordens auf, wonach er diesen ins Verderben führen kann.
} 
rung nicht nur für ,, nicht ausführbar", sondern auch für schädlich. Auch er sah den einzigen Ausweg in einer Auswanderung der Juden, da ,, es für drei Millionen Juden leichter sei zu emigrieren als für sechs Millionen Polen, die zudem bodenständiger sind". ${ }^{86}$

Der Judenhaß des Blatts Popławskis war ein neues, für die Befürworter der Assimilierung überraschendes Phänomen. Der Glos vertrat nämlich eine der Strömungen, die man im neunzehnten Jahrhundert progressiv nannte. Wenig später erschien auf der politischen Bühne des Königreichs die ,Nationaldemokratie" (ND, poln. Endecja), die sich bald ebenfalls zum Antisemitismus bekannte, ja ihn sogar in ihr Programm aufnahm, um so alle übrigen antijüdischen Gruppen - einschließlich der um den Glos zu absorbieren.

Die ND ging 1897 aus der seit 1886 bestehenden Liga Polska hervor. Ihr führender Kopf, Roman Dmowski, formulierte sein Programm schon etwas früher in dem in Galizien erscheinenden Prezeglad Wszechpolski. Die ND hatte zunächst in der Judenfrage keinen einheitlichen Standpunkt. Sie forderte keine Ausnahmerechte, meinte aber, daß die - ihrer Meinung nach verfrühte - Gleichberechtigung der Juden viel Schaden anrichtete. Bei den Juden Progressive und das ,fremde Element" unterscheidend, sprach sie sich im Prinzip für eine Assimilierung aus, bezweifelte jedoch, daß sie möglich wäre.

Den offenen Antisemitismus führte Dmowski in Programm und Ideologie der ND erst 1904 ein - in den ,,Gedanken eines modernen Polen", ${ }^{87}$ er entwickelte inn weiter 1909 in seiner Schrift zur "Judenfrage”. ${ }^{88}$ In der ersteren Broschüre schrieb er:

Der nationale Organismus sollte nur nach der Absorbierung dessen streben, was er assimilieren und zur Verstärkung des Wachstums und der Kraft des kollektiven Körpers umsetzen kann. Die Juden sind kein solches Element. Sie haben eine allzu ausgeprägte, durch -zig Jahrhunderte ihres Lebens ausgeformte Zivilisationsgestalt, als daß eine so junge, ihren Charakter erst ausbildende Nation wie die unsere sie in größerer Zahl assimilieren könnte, und wären vielmehr ihrerseits imstande, die Mehrzahl von uns geistig und teilweise auch physisch sich zu assimilieren [ . . ]. Die Verschmelzung mit einer größeren Menge dieses Elements wäre für uns verderblich, da es die jungen, schöpferischen Stoffe, auf die wir unsere Zukunft bauen, durch Elemente des Verfalls ersetzen würde. Eine gewisse, kleine Menge des jüdischen Elements müssen und können wir absorbieren und transformieren ohne großen Schaden für uns selbst. ${ }^{89}$

86 W. Ziemiński, ,Czem jest Izrael”, in: Glos, 1891, Nr 9.

${ }^{87}$ R. Dmowski, Myśli nowoczesnego Polaka, Krakau 1904.

8 Ders., Kwestya żydowska. Separatyzm Żydów i jego źródła, Warschau 1909.

${ }^{89}$ Ders., Myśli nowoczesnego Polaka, Warschau 1933, S. 202. 
Bei Dmowski stand nicht die Skepsis hinsichtlich der Möglichkeit der Assimilation im Vordergrund, sondern die Furcht vor ihren Folgen.

Die Scharen der Polen jüdischer Herkunft sind enorm gewachsen; aber es sind das Polen von immer geringerer Qualität [coraz bardziej tandetni]. Diese neue polnisch-jüdische Intelligenz hatte, gerade wegen ihrer großen Zahl, einfach mechanisch nicht die Möglichkeit, so tief in die polnische Sphäre einzudringen, wie das noch bei den wenigen Personen, die sich früher assimiliert hatten, der Fall gewesen war. Sie bildete ihre eigene jüdische Sphäre mit einer andersartigen Seele, einem andersartigen Verhältnis zum Leben, seinen Aufgaben. Überdies fühlte sie eine immer größere Kraft und strebte gemäß dem natürlichen Gang der Dinge, sei es bewußt, sei es unbewußt, zunehmend danach, der polnischen Gesellschaft ihre Begriffe und Aspirationen zu oktroyieren. Die Intelligenz in unserem Land, die polnisch spricht [. . .], teilte sich immer deutlicher in zwei Milieus - ein polnisches und ein jüdisches. Sie waren zwar nicht voneinander isoliert: es bildete sich zwischen ihnen eine mittlere Sphäre [. . . ]- die polnischjüdische, aber diese wurde zu einer Sphäre wechselseitiger Beeinflussung, eine Sphäre, in der die Polen auf die Juden und die Juden auf die Polen einwirkten und die im Endeffekt stärker polonisierte Juden und in gewissem Maße judaisierte Polen hervorbrachte. ${ }^{90}$

Die in der Publizistik damals häufig wiederholte Forderung, daß die Polen die ,,positiven Eigenschaften" der Juden übernehmen sollten, war nach der Ideologie der ND höchst gefährlich. Zwar stimmte die ND der ,, Absorbierung" einer gewissen Anzahl national Assimilierter zu, betonte aber, daß ihre Zahl klein bleiben mußte. Eine totale Polonisierung verlangend, sprach sie sich entschieden gegen alle anderen Phasen des Assimilationsprozesses aus - die Akkulturation, die Integration, die Amalgamierung. Das Polentum der akzeptierten Ausnahmen war am Grade ihrer Judenfeindlichkeit zu messen, d.h. die ND war nur die aufzunehmen bereit, die ihr Programm in der jüdischen Frage akzeptierten. Der Judenhaß Dmowskis, der dieses Programm bestimmte, war indessen nicht mehr der emotionale Antisemitismus der Rola, sondern berechnender: seine Theorie der Nation im ,,Ausnahmezustand" konstruierend, benutzte Dmowski den $\mathrm{Haß}$ als Bindemittel, wobei die Richtung dieses Hasses risikolos war. Durch die Wendung gegen die Juden suchte er das polnische Nationalbewußtsein zu stärken und hatte dabei weitgehend Erfolg.

Der Antisemitismus der ND hatte ein doppeltes Ziel: die Aktivierung der öffentlichen Meinung und zugleich ihre Unterjochung, wobei es nicht nur um die ,, aufgeklärte öffentliche Meinung" ging, an die sich die Positivisten gewandt hatten, sondern das massale Bewußtsein aller Klassen

Ders., Kwestya żydowska, a.a.O., S. $11 \mathrm{f}$. 
der Gesellschaft. Dazu bediente sich die Partei in ihrer Propaganda aller bis dahin entwickelten Methoden. Wie Ludwik Oberlaender schrieb:

Zur Begründung seiner Behauptungen benutzte R. Dmowski manchmal komplizierte gedankliche Konstruktionen, was den Gebrauch weitgehender Vereinfachungen bei der Bestimmung und Erklärung von Erscheinungen des sozialen Lebens bei ihm durchaus nicht ausschloß. Die Technik seines Wirkens war, was das anging, sehr interessant, und er handhabte sie sicherlich bewußt.

Oberlaender erwähnte auch die besonderen Merkmale der Dmowskischen Argumentationsweise: die Vermeidung von Abstraktionen; die Hervorhebung der Ausgangspunkte durch Symbole; das Appellieren an Instinkte und das jeweilige gesellschaftliche Bewußtsein; Geheimtuerei; Unbestimmtheit. Über Dmowski schrieb er:

Ein Rationalist, sich sehr wohl klar darüber, bis zu welch einem Grad die polnische Gesellschaft anfällig ist für ,,Legenden”, schuf er selbst Legenden und bediente sich ihrer bewußt zur Erreichung gewisser politischer Ziele. $[\ldots]$

Er appellierte an den Antisemitismus, wobei er sich realisierte, daß derselbe ein Produkt von niedrigen Instinkten ist, aber nicht wußte, welch eine Kraft er freisetzte. [. . .] Der Antisemitismus, der von ihm als Mittel zur Aktivierung der polnischen Kräfte gedacht war, brachte diese Kräfte für lange Zeit unter seine Gewalt und wuchs sich zu einem besonderen Gebilde aus, das seinen mächtigen Schatten auf das ganze Organisationsleben Polens warf. Neben dem großen Ideal der Wiederherstellung [Polens] existierte noch das Surrogat dieser Idee in der Gestalt des Antisemitismus. In ihm lebten sich die Massen aus. Selbst nach der Wiedererrichtung des Staats gab der Antisemitismus weiterhin die Illusion der schöpferischen Leistung, deren Fehlen von Zeit zu Zeit im täglichen Leben wahrgenommen wurde. ${ }^{91}$

Oberlaenders Bemerkungen sind von Bedeutung, insofern die Strömungen des politischen Denkens der ersten Hälfte des zwanzigsten Jahrhunderts ihre Quellen in den Traditionen des vorangegangenen Jahrhunderts haben. Die hier betrachtete Strömung gipfelte in Polen in dem Antisemitismus der ND. Darüber sollte erst der Hitlerismus noch hinausgehen.

Aus dem Polnischen übersetzt von J. Rojahn

91 L. Oberlaender, ,Ewolucja pogladów Narodowej Demokracji w sprawie żydowskiej", in: Miesiecznik Żydowski, 1932, Nr 1, S. 4-6. 